Article

\title{
Effect of 1,2,4,5-Benzenetetracarboxylic Acid on Unsaturated Poly(butylene adipate-co-butylene itaconate) Copolyesters: Synthesis, Non-Isothermal Crystallization Kinetics, Thermal and Mechanical Properties
}

\author{
Chin-Wen Chen $\mathbb{D}^{1}$, Te-Sheng Hsu, Kuan-Wei Huang and Syang-Peng Rwei * (1) \\ Institute of Organic and Polymeric Materials, Research and Development Center of Smart Textile Technology, \\ National Taipei University of Technology, No. 1, Sec. 3, Chung-Hsiao East Road, Taipei 10608, Taiwan; \\ cwchen@ntut.edu.tw (C.-W.C.); hsutesheng1991@gmail.com (T.-S.H.); wewe85625@gmail.com (K.-W.H.) \\ * Correspondence: f10714@ntut.edu.tw
}

Received: 14 April 2020; Accepted: 25 April 2020; Published: 19 May 2020

\begin{abstract}
Unsaturated poly (butylene adipate-co-butylene itaconate) (PBABI) copolyesters were synthesized through melt polymerization composed of 1,4-butanediol (BDO), adipic acid (AA), itaconic acid (IA) and 1,2,4,5-benzenetetracarboxylic acid (BTCA) as a cross-linking modifier. The melting point, crystallization and glass transition temperature of the PBABI copolyesters were detected around $29.8-49^{\circ} \mathrm{C}, 7.2-29^{\circ} \mathrm{C}$ and -51.1 and $-58.1^{\circ} \mathrm{C}$, respectively. Young's modulus can be modified via partial cross-linking by BTCA in the presence of IA, ranging between 32.19-168.45 MPa. Non-isothermal crystallization kinetics were carried out to explore the crystallization behavior, revealing the highest crystallization rate was placed in the BA/BI $=90 / 10$ at a given molecular weight. Furthermore, the thermal, mechanical properties, and crystallization rate of PBABI copolyesters can be tuned through the adjustment of BTCA and IA concentrations.
\end{abstract}

Keywords: poly(butylene adipate); poly(butylene itaconate); 1,2,4,5-benzenetetracarboxylic acid; partially cross-linking; thermoplastic; copolyester

\section{Introduction}

Aliphatic polyester, consisting of different lengths of $\mathrm{CH}_{2}$ group and ester bonds within the main-chain or side-chain, has been attracted more and more attention in recent years due to its lower melting temperature, reusable, flexibility, thermoplastic, easy processability and biodegradability [1-6]. Nevertheless, the thermal and mechanical characteristics of aliphatic polyesters can be enhanced via copolymerizing with different monomers to their suitability for a variety of commercial applications $[7,8]$. Unsaturated aliphatic polyester has been amended to practice the partial cross-linking via UV curing processing to adjust their physical property or through the cross-linking process with covalent bonds to produce thermoset-like copolyesters [9-12], or by combining it with epoxy materials [13-15]. The purpose of this operation is to achieve tremendous physical-chemical properties that provide unique characteristics of copolyesters, such as stronger hardness, higher rigidity, better tensile strength, chemical resistance and thermal stability [16-18].

Recently, copolyesters are developed rapidly due to the synthesis of new bio-based monomers and polymers. 2,5-furandicarboxylic acid is a popular bio-based aromatic diacid monomer consisting of a furan ring to replace the terephthalate acid, achieving an excellent gas barrier property [19-23]. Otherwise, the cross-linking modifiers are frequently undertaken to improve the thermal and mechanical 
properties of bio-based copolyesters [24-27]. By doing so, the bio-based aliphatic polyester can be formed a partial cross-linking network architecture by a small amount of multi-arm cross-linking modifiers, such as benzene-1,3,5-tricarboxylic acid and glycerol with the tri-arms; 2,2-bis (hydroxymethyl) 1,3-propanediol, ethylenediaminetetraacetic acid and 1,2,4,5-benzenetetracarboxylic acid with the tetra-arms; cyclohexane-1,2,3,4,5,6-hexacarboxylic acid and hexahydroxycyclohexane with the hexa-arms, etc. All the multi-arms functional modifiers were carried out below $0.5 \mathrm{~mole} \%$ to form partial cross-linking networking, for which the thermal and mechanical properties of copolyesters could be tuned via adjusting the modifier concentration, while still maintaining the processability of thermoplastics copolyesters. Chan et al. have been synthesized the poly (ethylene sebacate-co-ethylene adipate) (PESA) with benzene-1,3,5-tricarboxylic acid, indicating a high Young's modulus from 140 to $200 \mathrm{MPa}$ with varying adipate content due to partial cross-linking network created by the trimesic acid unit $[24,25]$. Hsu and coworkers developed a fully bio-based poly (butylene succinate-co-propylene succinate) (PBSPS) system with glycerol adjust the thermal-mechanical properties, revealing the PBSPS copolyesters could be transformed from elastic to rigid characteristics by increasing the glycerol concentration, and the elongation decreased from $800 \%$ to $20 \%$ [26]. Furthermore, Chen and colleagues developed a novel unsaturated aliphatic copolyester like poly (butylene adipate-co-butylene itaconate) (PBABI), which copolymerized with ethylenediaminetetraacetic acid (EDTA) to enhance the physical property, showing the cross-linking modifiers were the best choice to form the steric network structure to improve the mechanical and thermal properties of these kinds of aliphatic copolyesters $[27,28]$. Otherwise, another interesting tetra-functional chemical is 1,2,4,5-benzenetetracarboxylic acid (BTCA), so-called pyromellitic acid, which plays the same role as a cross-linking modifier to control the crystallization rate and increase the enthalpy of the melting point due to the benzene ring in the center of BTCA [29,30]. Furthermore, Karki et al. proposed the potential use of the BTCA as an attractive multivalent template to act as a switch in H-bonds supramolecular networking, which could be performed to create novel photoactive arrangement applications [31]. As mentioned above, the aliphatic polyester can form a partial cross-linking architecture by tri- or tetra-arms cross-linking modifiers to investigate the thermal, mechanical properties and crystallization kinetics behavior.

Herein, the straightforward preparation of a series of PBABI copolyesters with BTCA via melting polymerization was synthesized in this research. The BTCA modifier within copolyesters could be improved the thermal stability and maintained mechanical properties via a partial crosslinking structure. Different compositions of AA/IA were conducted to tune a melting point range around $30-50^{\circ} \mathrm{C}$ and at a constant BTCA ratio of $0.1 \mathrm{~mole} \%$ to generate the mechanical strength. Furthermore, the non-isothermal crystallization kinetics was carried out to examine the crystallization rate for PBABI copolyesters, exhibiting the fastest crystallization rate was placed in a BA/BI ratio of 90/10. Finally, the influence of unique ratios of BTCA between 0.05 to $0.2 \mathrm{~mole} \%$ at a fixed ratio of $\mathrm{BA} / \mathrm{BI}=90 / 10$ was also explored to observe fluctuations in thermal and mechanical properties and to accommodate the appropriate BTCA concentration in the PBABI copolyesters.

\section{Experimental}

\subsection{Materials}

The adipic acid (AA, 99.8\%) was supplied from Asahi Kasei Corporation. Itaconic acid (IA, 99\%) and 1,4-butanediol (BDO, 99\%) were purchased from the First Chemical Corporation (Taipei, Taiwan). The 1,2,4,5-benzenetetracarboxylic acid (BTCA, 97\%) was obtained from Vetec. The 4-Methoxyphenol $(99 \%)$, titanium butoxide $\left(\mathrm{Ti}(\mathrm{OBu})_{4}, 97 \%\right)$, deuterium trifluoroacetic acid (d-TFA, 99.5\%) and hexafluoroisopropanol (HFIP, 99\%) were provided from Aldrich (St. Louis, MO, USA). The dibutyltin dilaurate (DBTDL, 95\%) was attained from Alfa Aesar (Haverhill, MA, USA). All the chemicals were implemented in bulk polymerization via a $2 \mathrm{~L}$ reactor without any purification. 


\subsection{Sample Preparation}

PBABI copolyesters with BTCA were copolymerized via one-pot melt polymerization. First, AA, IA and BTCA were esterified with BDO, 4-Methoxyphenol as an inhibitor, DBTDL and Ti(OBu $)_{4}$ acting as a catalyst. A $2 \mathrm{~L}$ reactor was adopted in bulk copolymerization. The PBABI copolyesters represented to as $\mathrm{BA} / \mathrm{BI}=\mathrm{x} / \mathrm{y}$ correspond to the ratio of butylene adipate/butylene itaconate, where $\mathrm{x}$ and $\mathrm{y}$ are the molar ratio of AA and IA. The molar ratio of $[\mathrm{OH}] /[\mathrm{COOH}]$ was maintained at a molar ratio of $1.2 / 1$ in all synthesized PBABI copolyesters, and the different molar ratios of BA/BI $=100 / 0,95 / 5,90 / 10$, 85/15, 80/20 were chosen. The 4-Methoxyphenol, DBTEL and Ti(OBu $)_{4}$ were set in $0.5 \mathrm{wt} \%, 1 \mathrm{wt} \%$ and $0.5 \mathrm{wt} \%$, respectively. The concentration of the BTCA with different BA/BI ratios was carried out at $0.1 \mathrm{~mole} \%$. To consider the influence of various BTCA concentrations, the BA/BI ratio was fixed at $90 / 10$ with the BTCA concentrations of $0.05,0.1$ and 0.2 mole\%. The exact synthesizing conditions of the $2 \mathrm{~L}$ reactor have been described clearly in our previous report [27], and the detailed synthesis route was represented in Scheme 1.

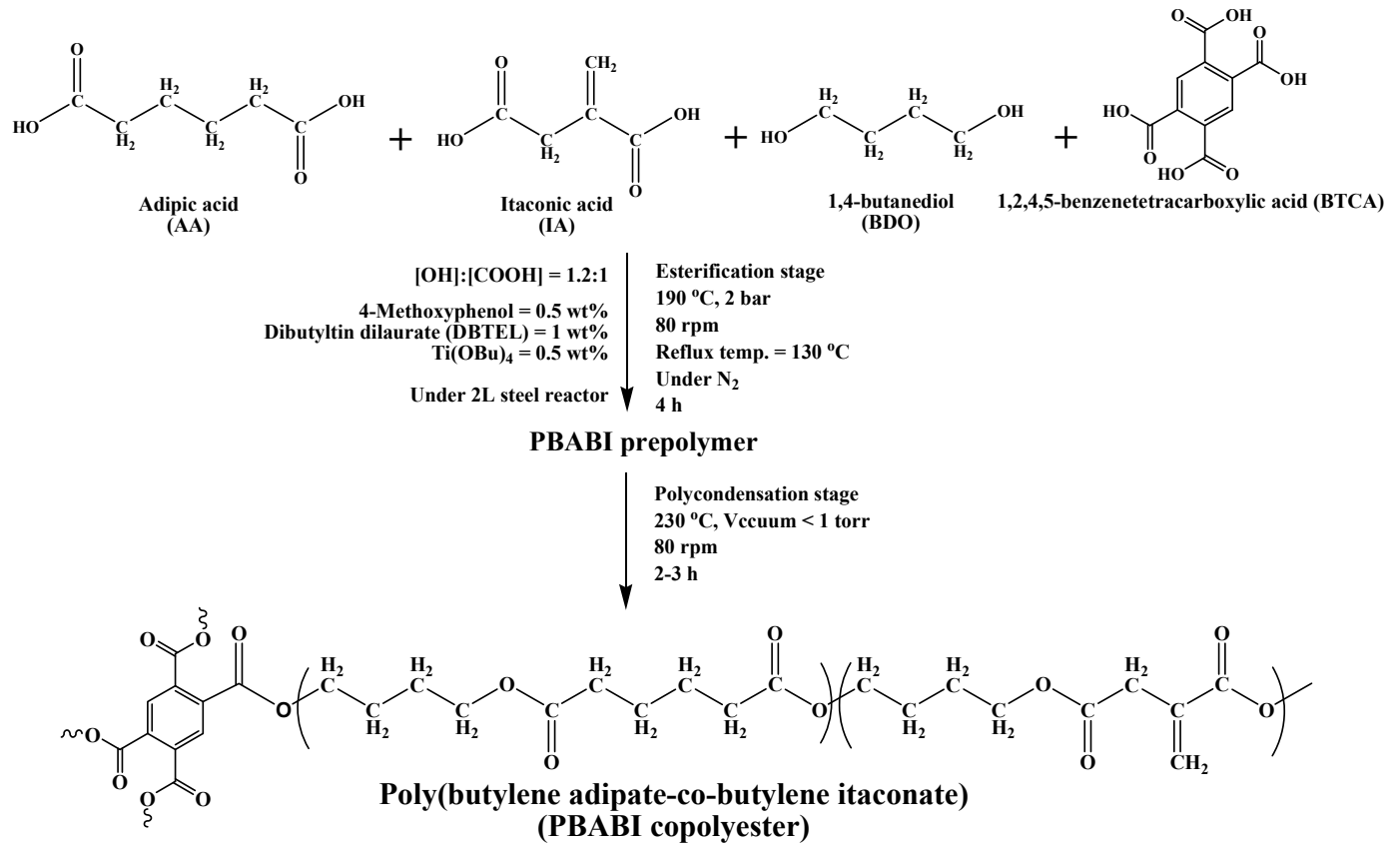

Scheme 1. Synthesis route of poly (butylene adipate-co-butylene itaconate) (PBABI) copolyester.

\subsection{Measurements}

\subsubsection{Nuclear Magnetic Resonance Spectroscopy $\left({ }^{1} \mathrm{H}\right.$ NMR)}

${ }^{1} \mathrm{H}$ NMR spectrometer (JEOL ECZ600R $600 \mathrm{MHz}$, Tokyo Japan) was employed to identify the chemical structure of the synthesized PBABI copolyesters. At first, $100 \mathrm{mg}$ of the synthesized copolyester was dissolved in d-TFA of $1 \mathrm{~mL}$; then, the solutions were then transferred into $5 \mathrm{~mm}{ }^{1} \mathrm{H}$ NMR sample tubes. All the analyses were performed at room temperature and achieved 128 scans to collect the data for further analysis.

\subsubsection{Fourier Transform Infrared Spectroscopy (FT-IR)}

FTIR Spectrometer (PerkinElmer, Waltham, MA, USA) was performed to measure the synthesized PBABI copolyesters in attenuated total reflection mode with an average signal of 32 co-added scans at a resolution of $4 \mathrm{~cm}^{-1}$ over a wavenumber range of $400-4000 \mathrm{~cm}^{-1}$. 


\subsubsection{Intrinsic Viscosity (I.V.)}

The synthesized PBABI copolyesters were measured in $1.0 \mathrm{~g} \mathrm{dL}^{-1}$ within a mixture of phenol and tetrachloroethane in a weight ratio of $60 / 40$ was obtained using an Ubbelodhe viscometer at $25 \pm 0.05^{\circ} \mathrm{C}$. The IV of each sample was calculated using the Solomon-Ciuta equation:

$$
[\eta]=\frac{\sqrt{\left\{2\left[\frac{t}{t 0}-\ln \left(\frac{t}{t 0}\right)-1\right]\right\}}}{C}
$$

where $C$ is the concentration of the solution; $t$ is the flow time of the sample solution, and $t_{0}$ is the flow time of the pure solvent. Measurements of each sample were made five times to calculate the averaged IV values and tabulated in Table 1.

Table 1. Gel permeation chromatography (GPC) results and the I.V. values of PBABI copolyesters.

\begin{tabular}{|c|c|c|c|c|}
\hline Sample & I.V. $\left(\mathrm{dL} \mathrm{g}^{-1}\right)$ & $M_{n}\left(g\right.$ ole $\left.^{-1}\right)$ & $M_{w}\left(g_{\text {mole }}-1\right)$ & $\mathrm{M}_{\mathrm{w}} / \mathrm{M}_{\mathrm{n}}$ (PDI) \\
\hline $\mathrm{BA} / \mathrm{BI}=100 / 0$ & 0.75 & 16,787 & 36,064 & 2.15 \\
\hline $\mathrm{BA} / \mathrm{BI}=95 / 5$ & 1.17 & 26,281 & 64,126 & 2.44 \\
\hline $\mathrm{BA} / \mathrm{BI}=90 / 10$ & 1.23 & 31,970 & 80,564 & 2.52 \\
\hline $\mathrm{BA} / \mathrm{BI}=85 / 15$ & 1.27 & 34,791 & 134,641 & 3.87 \\
\hline $\mathrm{BA} / \mathrm{BI}=80 / 20$ & 1.25 & 39,024 & 161,950 & 4.15 \\
\hline
\end{tabular}

\subsubsection{Gel Permeation Chromatography (GPC)}

The Viscotek GPC System (1122 pump, 2707 Auto-Injector, 270 LS Laser Light Scattering Detector/Viscometer, Shodex 71 RI detector, OmniSEC 4.6 Station, Malvern, UK) was used with the HFIP $806 \mathrm{M}$ Shodex column (Size: diameter and length in $8.0 \mathrm{~mm}$ and $300 \mathrm{~mm}$, particle size is $10 \mu \mathrm{m})$. The synthesized PBABI copolyesters were dissolved in HFIP for $12 \mathrm{~h}$ and then filtered through a $0.2 \mu \mathrm{m}$ PTFE filter membrane. Then, the oven temperature, flow rate and analysis time were set at

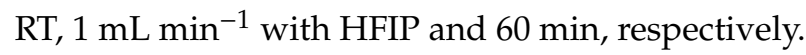

\subsubsection{Differential Scanning Calorimetry (DSC)}

DSC instrument (Hitachi High Tech. DSC-7000, Tokyo, Japan) was employed to evaluate the $T_{\mathrm{m}}$ $T_{\mathrm{c}}, \Delta H_{\mathrm{m}}$ and $\Delta \mathrm{H}_{\mathrm{c}}$ of the PBABI copolyesters. The measurement was set at a heating rate of $10{ }^{\circ} \mathrm{C} \mathrm{min}-1$ from -50 to $150^{\circ} \mathrm{C}$ and held for $5 \mathrm{~min}$ to eliminate thermal history. Then, these samples were cooled to $-50{ }^{\circ} \mathrm{C}$ at a cooling rate of $10{ }^{\circ} \mathrm{C} \mathrm{min}-1$ for the first cycle. After that, the second cycle of the reheating process from -50 to $150{ }^{\circ} \mathrm{C}$ at the same heating rate of $10^{\circ} \mathrm{C} \mathrm{min}-1$. All the DSC measurements were applied in a nitrogen atmosphere with aluminum pans.

\subsubsection{Thermogravimetric Analysis (TGA)}

TGA (Hitachi, STA 7200, Japan) was adopted to measure the degradation temperature of the synthesized PBABI copolyesters. The synthesized samples in the weight range of 5-10 mg were heated from 50 to $600{ }^{\circ} \mathrm{C}$ at a heating rate of $10{ }^{\circ} \mathrm{C} \mathrm{min}-1$ under a nitrogen atmosphere. The degradation temperature from the TGA curve was determined at $5 \%$ weight loss $\left(T_{d-5 \%}\right)$.

\subsubsection{Dynamic Mechanical Analyzer (DMA)}

The DMA (Tech Max DMS 6100, Tokyo, Japan) was adopted to estimate the viscoelastic properties of the PBABI copolyesters, including storage modulus $\left(\mathrm{E}^{\prime}\right)$, loss modulus $\left(\mathrm{E}^{\prime \prime}\right)$ and loss tangent $(\tan \delta)$. The synthesized samples were tested in compression mode with $150 \mathrm{mN}$ at a frequency of $1 \mathrm{H}_{\mathrm{z}}$ and a set temperature range from -150 to $0{ }^{\circ} \mathrm{C}$ at a heating rate of $10^{\circ} \mathrm{C} \mathrm{min}-1$. The sample was prepared at a size of $30 \mathrm{~mm}$ in length, $10 \mathrm{~mm}$ in width and $2 \mathrm{~mm}$ in thickness. 


\subsubsection{X-ray Diffraction (XRD)}

The film was prepared by hot-melt mechanical compression with a temperature of $80{ }^{\circ} \mathrm{C}$ and a pressure of $50 \mathrm{Kgf} \mathrm{cm}^{-2}$ for $1 \mathrm{~min}$; then the XRD pattern of the PBABI film was collected using a Malvern Panalytical $X^{\prime} \mathrm{Pert}^{3}$ powder diffractometer (Malvern, UK) with $\mathrm{Cu} \mathrm{K}_{\alpha}$ radiation $(\lambda=0.154 \mathrm{~nm})$ in $2 \theta$ from 10 to 40 degrees at room temperature with a scanning speed of $0.2^{\circ} \mathrm{min}^{-1}$.

\subsubsection{Tensile Test}

The hot melt compression molding was performed to prepare dumb-bell shaped specimens of the synthesized PBABI copolyesters at $80^{\circ} \mathrm{C}$ and $3 \mathrm{~kg} \mathrm{~cm}^{-2}$ in $2 \mathrm{~min}$. Then, the measurements were taken at a crosshead speed of $50 \mathrm{~mm} \mathrm{~min}^{-1}$ using Cometech QC-508M2F (Taichung, Taiwan) based on the ASTM d638 Type IV (Length: $33 \mathrm{~mm}$, width: $6 \mathrm{~mm}$, thicken: $3 \mathrm{~mm}$ ) standard to attain a stress-strain curve. The yield strength, elongation at break, and Young's modulus were evaluated from the stress-strain curve. All the data were obtained on an averaged value of 5 specimens. The sample was prepared at a size of $30 \mathrm{~mm}$ in length, $10 \mathrm{~mm}$ in width and $2 \mathrm{~mm}$ in thickness.

\subsubsection{Non-isothermal Crystallization Kinetic Procedures}

All the PBABI copolyesters were carried out with a DSC instrument (Hitachi High Tech. DSC-7000, Japan) calibrated with Indium. All measurements were performed under nitrogen gas and atmosphere, and the weight of all samples was chosen in $5 \mathrm{mg}$ sealed within an aluminum pan. Subsequently, the samples were heated up from room temperature to $150{ }^{\circ} \mathrm{C}$ at a rate of $10^{\circ} \mathrm{C} \mathrm{min}{ }^{-1}$, kept at this temperature for $5 \mathrm{~min}$ to eliminate any thermal history, then cooled down to $-50{ }^{\circ} \mathrm{C}$ at a different cooling rate of 2,5 and $10^{\circ} \mathrm{C} \mathrm{min}^{-1}$, respectively. The exothermal curves of heat flow as a function of temperature were recorded to proceed the non-isothermal crystallization kinetics evaluation.

\section{Results and Discussion}

\subsection{The Effect of the BA/BI Ratio of PBABA Copolyesters with a BTCA Concentration of 0.1 mole\%}

Figure 1 displays the chemical structure of synthesized PBABI copolyester at a ratio of BA/BI $=90 / 10$ was confirmed by ${ }^{1} \mathrm{H}$ NMR spectra, and the other ratios of BA/BI were presented in Figure S1. The resonance peaks of PBABI copolyesters were identified and assigned in $\mathrm{H}_{1}(1.877-2.124 \mathrm{ppm}$, 3, 4- $\mathrm{CH}_{2}$ of adipic acid), $\mathrm{H}_{2}\left(1.960-2.206 \mathrm{ppm}, 2\right.$, 3- $\mathrm{CH}_{2}$ of 1.4-butanediol), $\mathrm{H}_{3}$ (2.643-2.889 ppm, 2, 5- $\mathrm{CH}_{2}$ of adipic acid), $\mathrm{H}_{4}$ (3.689-3.912 ppm, 2- $\mathrm{CH}_{2}$ of itaconic acid), $\mathrm{H}_{5}$ (4.404-4.648 ppm, 1, 4- $\mathrm{CH}_{2}$ of 1.4-butanediol), $\mathrm{H}_{6}\left(6.031-6.142 \mathrm{ppm},-\mathrm{C}=\mathrm{CH}_{2}\right.$ of itaconic acid), $\mathrm{H}_{7}\left(6.295-6.737 \mathrm{ppm},-\mathrm{C}=\mathrm{CH}_{2}\right.$ of itaconic acid) and $\mathrm{H}_{8}(6.895-8.320 \mathrm{ppm},-\mathrm{CH}$ of the benzenic ring in BTCA. All the resonance peaks in ppm, the integral ratio, and the calculated composition of IA for PBABI copolyesters were listed in Table S1. The ratios of $\mathrm{C}=\mathrm{C}$ bond of the IA were calculated in $4.07 \%, 4.21 \%, 8.48 \%$ and $9.53 \%$ for $\mathrm{BA} / \mathrm{BI}=95 / 5,90 / 10,85 / 15$ and $80 / 20$, respectively, implying the $\mathrm{C}=\mathrm{C}$ bond of the IA may possibly isomerize into monomethyl fumarate, which has a significantly lower reactivity and cannot be detected in the NMR spectrum [32]. Furthermore, the concentration of the $\mathrm{C}=\mathrm{C}$ bond of IA can be preserved near $50 \%$ in each PBABI copolyester during melt polymerization at high-temperature of $230{ }^{\circ} \mathrm{C}[33,34]$, implying the $50 \% \mathrm{C}=\mathrm{C}$ bond of IA may be reacted to be a saturated $\mathrm{C}-\mathrm{C}$ bond in forming a partial cross-linking structure, and the residual $\mathrm{C}=\mathrm{C}$ bond could participate in the successive UV curing procedure to adjust the mechanical properties of the PBABI copolyesters [27]. Brännström et al. studied the poly (butylene itaconate-co-butylene succinate) (PBIBSu) system via FT-IR analysis, which indicated the degree of curing of the PBIBSu copolyesters could be located around $50-75 \%$, with various ratios of IA and SuA. Furthermore, the IA is not sufficient reactivity under melt polymerization, and the conversion of $\mathrm{C}=\mathrm{C}$ in cross-linking formation could be made at $75 \%$ [35]. Consequently, staying near a $50 \%$ ratio for the $\mathrm{C}=\mathrm{C}$ concentration of IA was critical for enhancing the unsaturated $\mathrm{C}=\mathrm{C}$ to saturated $\mathrm{C}-\mathrm{C}$, to form a higher partial network architecture, which may decrease the backbone movement and the crystal region. 

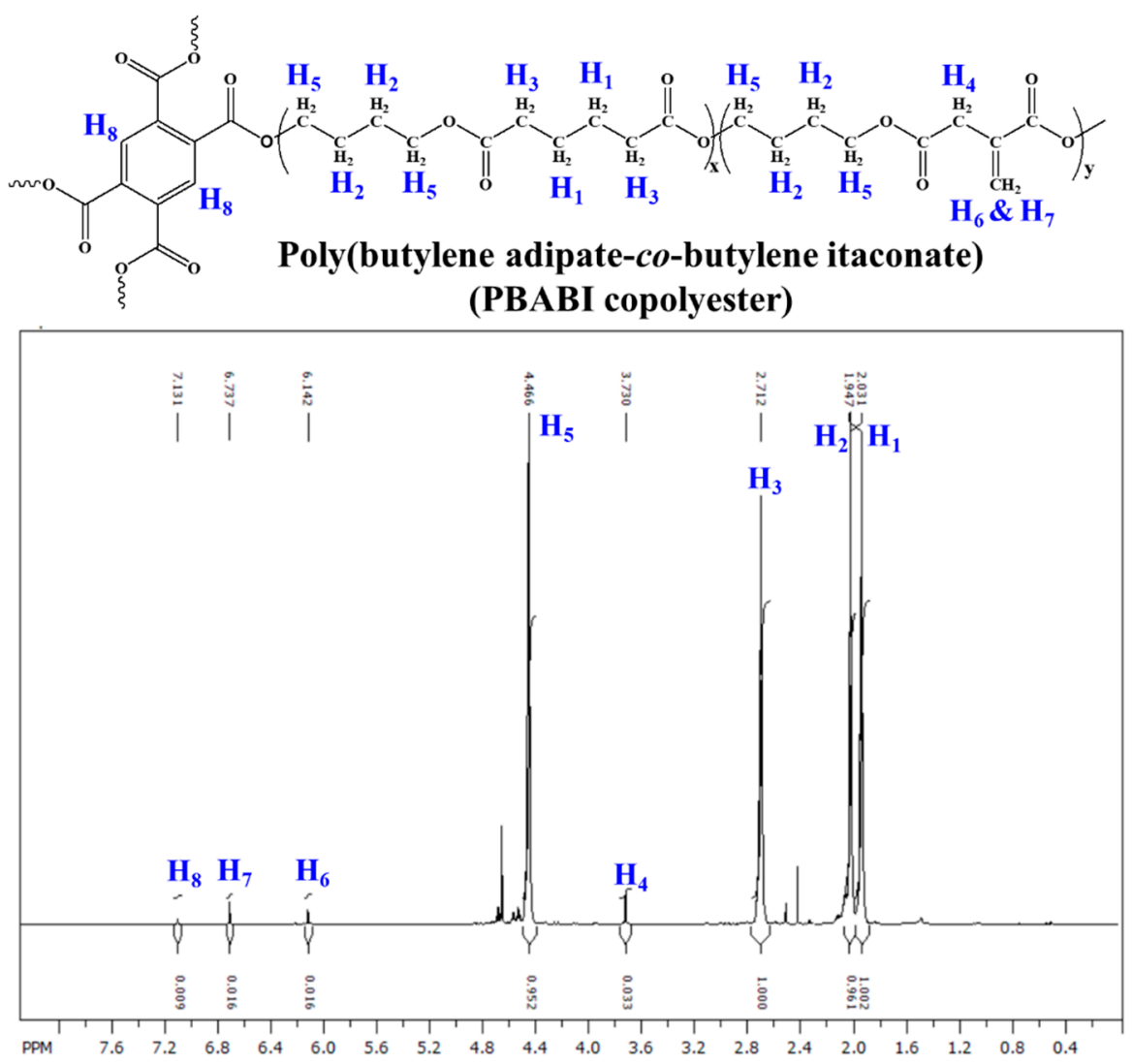

Chemical Shift (ppm)

Figure 1. ${ }^{1} \mathrm{H}$ NMR spectra of PBABI copolyester at a ratio of $\mathrm{BA} / \mathrm{BI}=90 / 10$.

Figure 2 shows the FT-IR spectra of synthesized PBABI copolyesters, for which the absorption peaks related to the asymmetry and symmetry $\mathrm{C}-\mathrm{H}$ stretch have been identified at 2954 and $2876 \mathrm{~cm}^{-1}$, respectively. The stretching vibration of the $\mathrm{C}=\mathrm{O}$ in the ester bond at $1724 \mathrm{~cm}^{-1}$, a C-H bend absorption peak at a value of $1460 \mathrm{~cm}^{-1}$, and a band of $1254 \mathrm{~cm}^{-1}$ were correlated to $\mathrm{C}-\mathrm{O}$ of the ester bond. The out-of-plane of the benzene ring within BTCA has a feature peak of around $745 \mathrm{~cm}^{-1}$. The most significant peak was discovered and remarked in 1639 and $817 \mathrm{~cm}^{-1}$, which was corresponding to the $C=C$ bond stretching vibration within IA. Hence, the absorption peaks in 1639 and $817 \mathrm{~cm}^{-1}$ can be enhanced as raising the of IA concentration, explaining that the IA molecule was successfully copolymerized into a main-chain of PBABI copolyesters. Additionally, the $\mathrm{C}=\mathrm{C}$ bond of IA was protected by radical inhibitor, 4-methoxyphenol, even though melt polymerization at a high temperature of $230^{\circ} \mathrm{C}$, with further UV curing, to control the mechanical properties of the PBABI copolyesters [27,32]. Tang et al. found that IA-based copolyesters could form a partial cross-linked structure through $\mathrm{C}=\mathrm{C}$ of IA, using methyl methacrylate as an initiator to improve the mechanical property, after irradiation via the UV curing process [36].

Molecular weights and I.V. values of PBABI copolyesters were tabulated in Table 1. The I.V. values of PBABI copolyesters were valued at $0.75,1.17,1.23,1.27$ and $1.25 \mathrm{dL} \mathrm{g}^{-1}$ with gradually increasing the IA content by 5 mole\%, suggesting chain entanglement can be enhanced by raising the IA concentrations to elevate the I.V. value. Moreover, the $M_{n}$ shows a wide range of 16,787 to $39,024 \mathrm{~g} \mathrm{~mole}^{-1}$ implied that the polymerization degree of PBABI copolyesters could be improved with an increase of IA ratios to obtain a higher value of $\mathrm{M}_{n}$ under identical synthesizing procedures. The $\mathrm{M}_{\mathrm{W}}$ had considerable values ranged from 36,064 to $161,950 \mathrm{~g} \mathrm{~mole}^{-1}$, reflecting that the PBABI copolyesters may be formed more great globule structures by a partial cross-linking structure in the presence of IA and BTCA. Furthermore, the polydispersion index values ranged from 2.15 to 4.15, 
resulting from a partial cross-linking structure for PBABI copolyesters. These results have a similar trend with the literature, and the PDI values are in a range of 1754 to 7.123 as an IA increased [24-27].

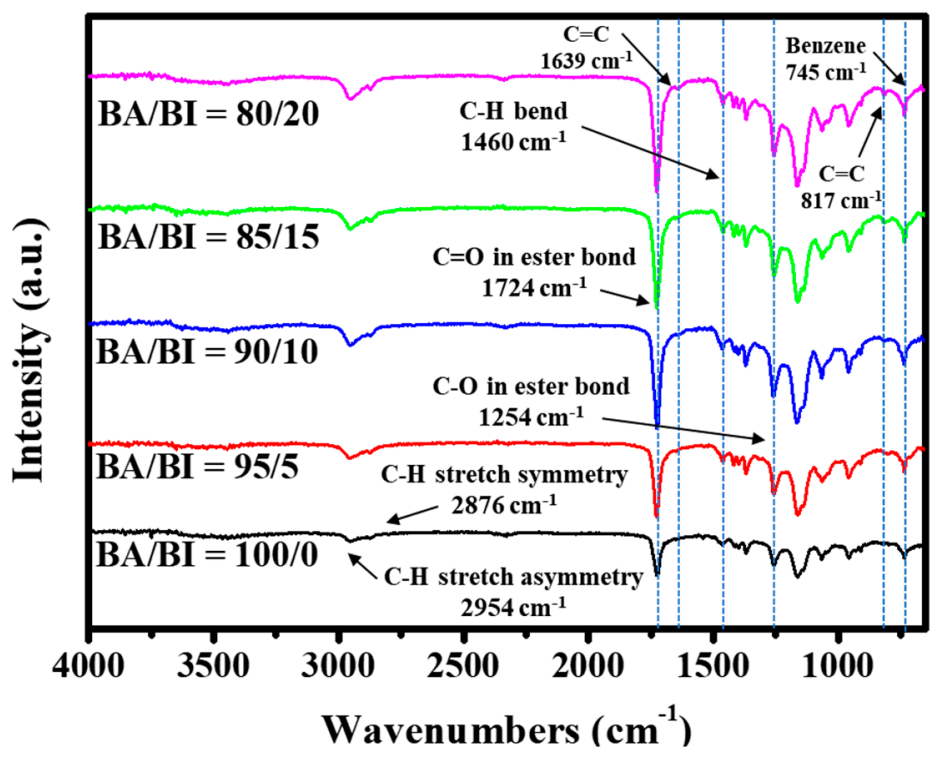

Figure 2. FT-IR spectra of PBABI copolyesters.

DSC cooling curves of the first cycle display in Figure 3a and reheating curve of the second-cycle in Figure $3 b$ indicated the crystallization in PBABI copolyesters occurred during cooling procedures, and the melting behavior observed in the subsequent reheating at a rate of $10^{\circ} \mathrm{C} \mathrm{min}^{-1}$. A single crystallization peak was noticed clearly around $7.2-29{ }^{\circ} \mathrm{C}$ at different BA/BI ratios during the cooling process, suggesting that the molecular chain of PBABI copolyester was easy to pack into the ordered phase [36]. A broader crystallization peak was achieved when the IA concentration was increased to $20 \mathrm{~mole} \%$, implying a higher IA content could hinder the molecular chain from packing into the ordered state, and disrupt the crystallization region of the AA-rich domain. All the thermal properties are shown in Table 2 , and the value of $\mathrm{T}_{\mathrm{m}}$ reduced from 49 to $29.8^{\circ} \mathrm{C}$, as IA concentration increased to $20 \mathrm{~mole} \%$. Furthermore, After removing the thermal history, the melting peak of the PBABI copolyesters was shown to be in a continuous double peak, demonstrating that a competitive effect may exist in the crystallization zone of AA and IA, within the PBABI copolyesters, during melt polymerization $[37,38]$. The $\Delta H_{\mathrm{m}}$ decreased from 57.3 to $45 \mathrm{~mJ} \mathrm{mg}^{-1}$, as IA increased, indicating that the crystallization region can be disrupted in the presence of the IA molecule. Furthermore, all the thermal properties, degradation temperature, crystallinity and glass temperatures were decreased when the IA concentration increased.
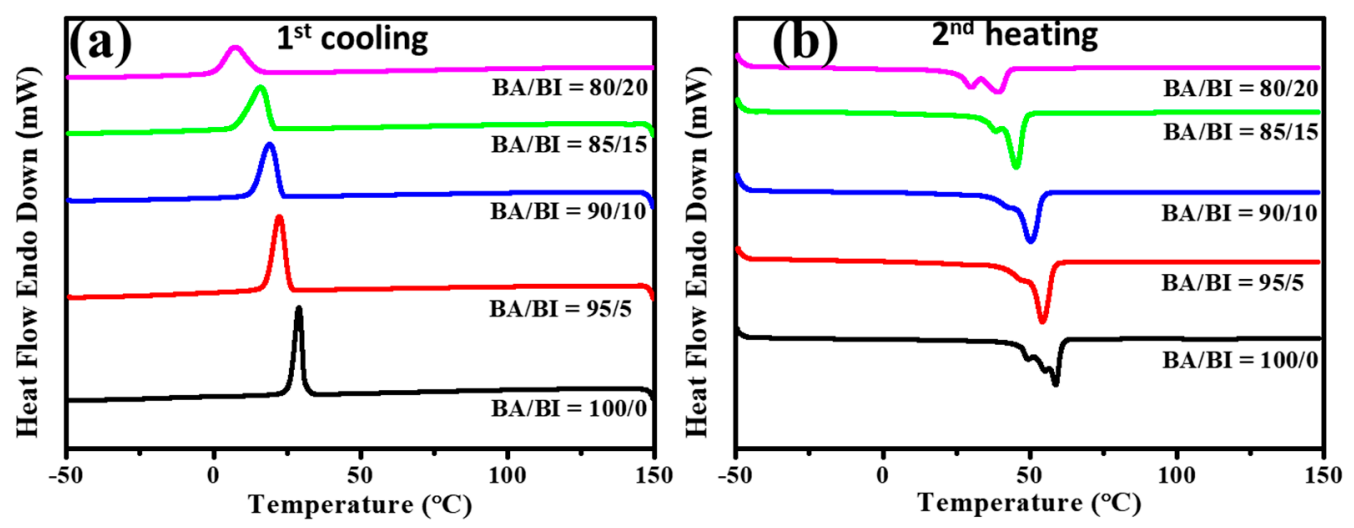

Figure 3. DSC trace of PBABI copolyesters: (a) cooling curves in the first cycle and (b) reheating curves in the second cycle. 
Table 2. Thermal properties of PBABI copolyesters.

\begin{tabular}{|c|c|c|c|c|c|c|c|}
\hline Sample & $\begin{array}{l}{ }^{*} T_{\mathrm{g}} \\
\left({ }^{\circ} \mathrm{C}\right)\end{array}$ & $\begin{array}{c}T_{\mathrm{c}} \\
\left({ }^{\circ} \mathrm{C}\right)\end{array}$ & $\begin{array}{c}\Delta H_{\mathrm{c}} \\
\left(\mathrm{mJ} \mathrm{mg^{-1 }}\right)\end{array}$ & $\begin{array}{l}T_{\mathrm{m}} \\
\left({ }^{\circ} \mathrm{C}\right)\end{array}$ & $\begin{array}{c}\Delta H_{\mathrm{m}} \\
\left(\mathrm{mJ} \mathrm{mg} \mathrm{mg}^{-1}\right)\end{array}$ & $\begin{array}{c}T_{\mathrm{d}-5 \%} \\
\left({ }^{\circ} \mathrm{C}\right)\end{array}$ & $\begin{array}{l}{ }^{\#} X_{c} \\
(\%)\end{array}$ \\
\hline $\mathrm{BA} / \mathrm{BI}=100 / 0$ & -51.1 & 29.0 & -60.6 & 49.0 & 57.3 & 341.2 & 42.4 \\
\hline $\mathrm{BA} / \mathrm{BI}=95 / 5$ & -54.6 & 22.5 & -59.4 & 47.4 & 56.0 & 346.5 & 41.6 \\
\hline $\mathrm{BA} / \mathrm{BI}=90 / 10$ & -58.1 & 18.9 & -57.6 & 42.6 & 52.7 & 348.1 & 40.3 \\
\hline $\mathrm{BA} / \mathrm{BI}=85 / 15$ & -57.6 & 15.8 & -57.3 & 38.4 & 52.2 & 336.1 & 39.9 \\
\hline $\mathrm{BA} / \mathrm{BI}=80 / 20$ & -54.6 & 7.2 & -47.5 & 29.8 & 45.0 & 332.6 & 34.2 \\
\hline
\end{tabular}

Figure 4 presents the TGA profiles for PBABI copolyesters and the $5 \mathrm{wt} \%$ weight loss temperature $\left(T_{\mathrm{d}-5 \%}\right)$ in Figure $4 \mathrm{a}$ occurred around $332.6-341.2{ }^{\circ} \mathrm{C}$, indicating all samples have excellent thermal stability since the $T_{d-5 \%}$ of all PBABI copolyesters was over $300{ }^{\circ} \mathrm{C}$, and the $T_{d-5 \%}$ values of PBABI copolyesters declined about $10^{\circ} \mathrm{C}$ by increasing the IA content to $20 \mathrm{~mole} \%$, as can be seen in Table 2 . Figure $4 \mathrm{~b}$ displayed the derivative thermogravimetry (DTG), indicating a degradation speed was increased, and degradation temperature was decreased, as an increase of IA content. Hence, the thermal stability of the PBABI copolyesters could be diminished with an increase of IA concentration, as a result of the interruption of the crystallization area.
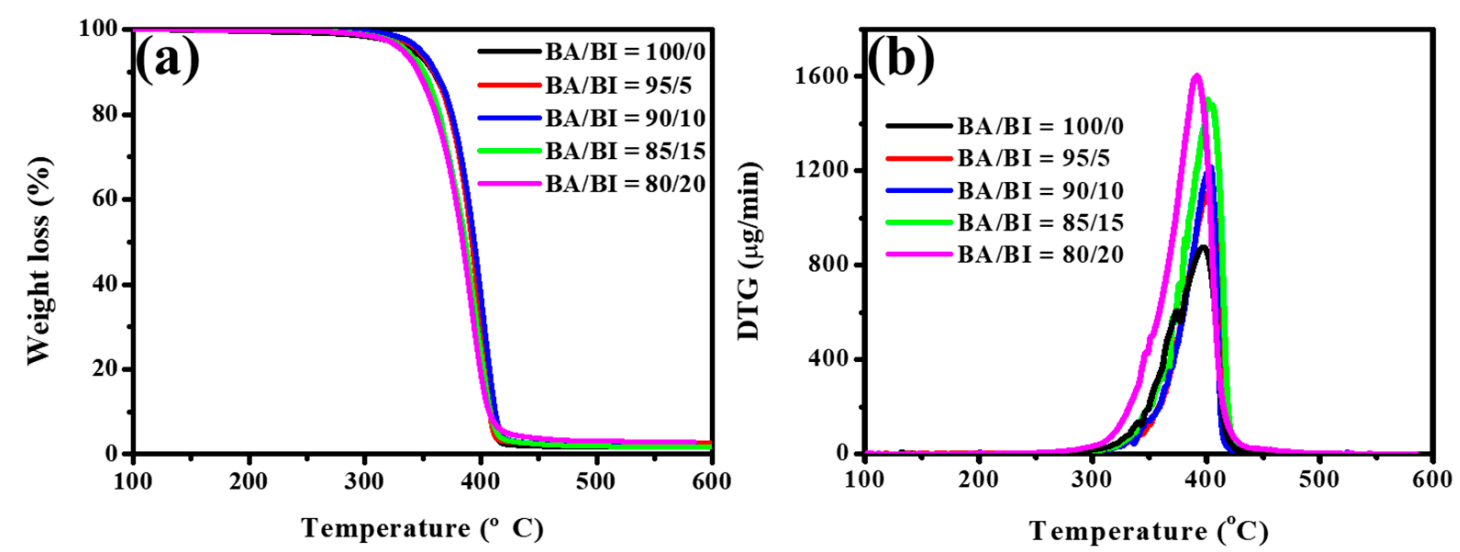

Figure 4. (a) Weight loss and (b) derivative thermogravimetry (DTG) as a function of temperature of PBABI copolyesters with different BA/BI ratios.

Figure 5 displays the DMA results of the PBABI copolyesters. The glass transition temperature $\left(T_{\mathrm{g}}\right)$ was obviously obtained at the peak of $\tan \delta$, and observed a stable value range from -54.6 and $-58.1^{\circ} \mathrm{C}$ in the presence of IA, as shown in Figure 5a. The results suggested that the values of $\mathrm{T}_{\mathrm{g}}$ were not correlated with the increase of IA concentration in the existence of BTCA. The BTCA as a modifier may play an essential role in maintaining the stability of the disordered region at relatively low temperature below $-50{ }^{\circ} \mathrm{C}$, even when the IA ratio was higher, due to the double-bond within IA, which can maintain the amorphous regime. The $\beta$-relaxation was also observed around $-100{ }^{\circ} \mathrm{C}$, which was correlated to the motion in the $\mathrm{R}-\mathrm{C}=\mathrm{CH}_{2}$ group, within IA, and the motion of the $\mathrm{R}-\mathrm{CH}_{2}$ group within the molecular side-chain. As can be seen in Figure 5b, $\mathrm{E}^{\prime}$ decreased when the temperature was raised above $T_{\mathrm{g}}$ in the rubbery state because the double-bond within IA could be induced to disturb and damage the regularity of the molecular chain in the amorphous region, to decrease the $E^{\prime}$ in the rubbery plateau region [39]. 

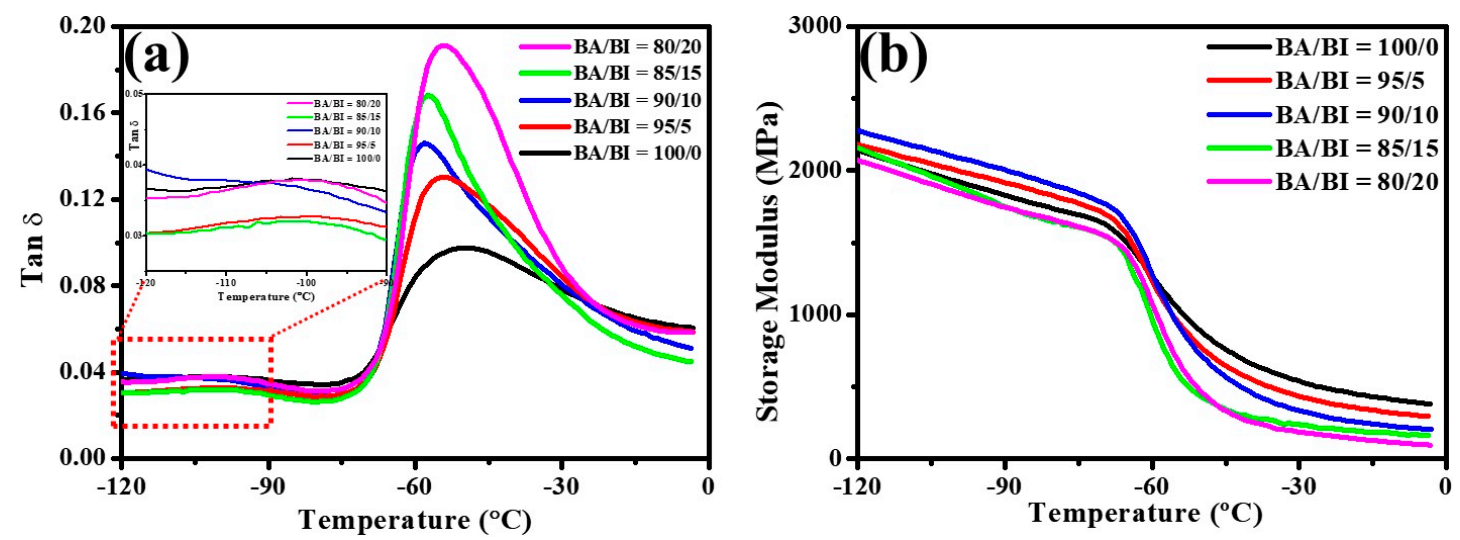

Figure 5. Dynamic mechanical analyzer (DMA) results for (a) Tan $\delta$ and (b) storage modulus of PBABI copolyesters.

Figure 6 displays the XRD results of PBABI copolyesters in a $2 \theta$ range of $10-40^{\circ}$. The feature peak of XRD in all ratio of BA/BI was carried out around the $2 \theta$ values of $21.75^{\circ}, 22.41^{\circ}$ and $24.12^{\circ}$ for the crystal lattices of (110), (020) and (020), respectively, which were related to the $\alpha$-phase of virgin PBA [38,40-44]. Furthermore, all the XRD patterns of PBABI copolyesters in different BA/BI ratios have similar patterns compared to $\mathrm{PBA}$, demonstrating that the crystal lattice of the $\mathrm{BA}$ unit could not be perturbed by the existence of the BI unit. Otherwise, PBABI copolyesters displayed crystallinity values in $42.4 \%, 41.6 \%, 40.3 \%, 39.9 \%$ and $34.2 \%$ for BA/BI $=100 / 0,95 / 5,90 / 10,85 / 15$ and $80 / 20$, respectively, indicated sufficient IA content could interrupt chain packing into the ordered state to lowering crystallinity. Generally, the crystallinity of the PBABI copolyesters was around $40 \%$, which specified that the crystal formation was favored by the overall van der Waals interaction and the BTCA, to form partial cross-linking polyesters. To the best of knowledge, PBABI copolyesters displayed an increase of chain flexibility with increasing BI content. This increased chain flexibility may have enhanced a more-effective rearrangement of the polymer chains, allowing van der Waals interactions to encourage a more significant degree towards the formation of the crystalline domain and may have increased the crystallinity. Unfortunately, the benzene ring of BTCA provided a crucial role in providing a robust steric hindrance to limit the chain rearrangement into the crystallization regime, revealing the crystallinity decreased with an increase of IA concentrations. Generally speaking, the calculated crystallinities obtained via DSC have similar trends than those from XRD results, suggesting a beneficial relationship between the two measurements.

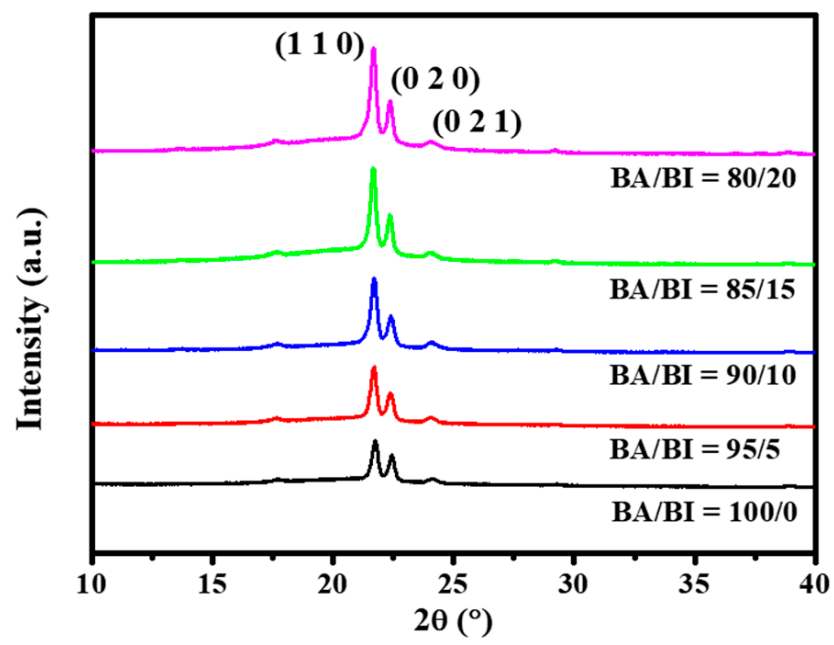

Figure 6. X-ray Diffraction (XRD) patterns of PBABI copolyesters with different BA/BI ratios. 
The stress-strain curve was taken via tensile tests, including the yield strength, elongation at the break, and Young's modulus of the PBABI copolyesters, as shown in Figure 7 and tabulated in Table 3. In the tensile test, the macroscopic deformation of $\mathrm{BA} / \mathrm{BI}=100 / 0$ was established at the highest strength of $15.19 \mathrm{MPa}$ and elongation at break of $56.13 \%$, and all the mechanical properties decreased and exhibited a brittle characteristic when the IA concentration increased above 10 mole\%. The yield strength, elongation and Young's modulus at different BA/BI ratios were evaluated in a range of 5.81-15.19 MPa, $13.78-56.13 \%$ and $32.19-168.45 \mathrm{MPa}$, respectively, suggesting mechanical properties of PBABI copolymers was reduced with an increase of IA concentration due to decrease of the crystallinity. Similarly, Panic et al. have been proposed that an increase of the itaconate concentration could worsen mechanical properties and hinder the packing behavior of the molecular chain occurrence [45].

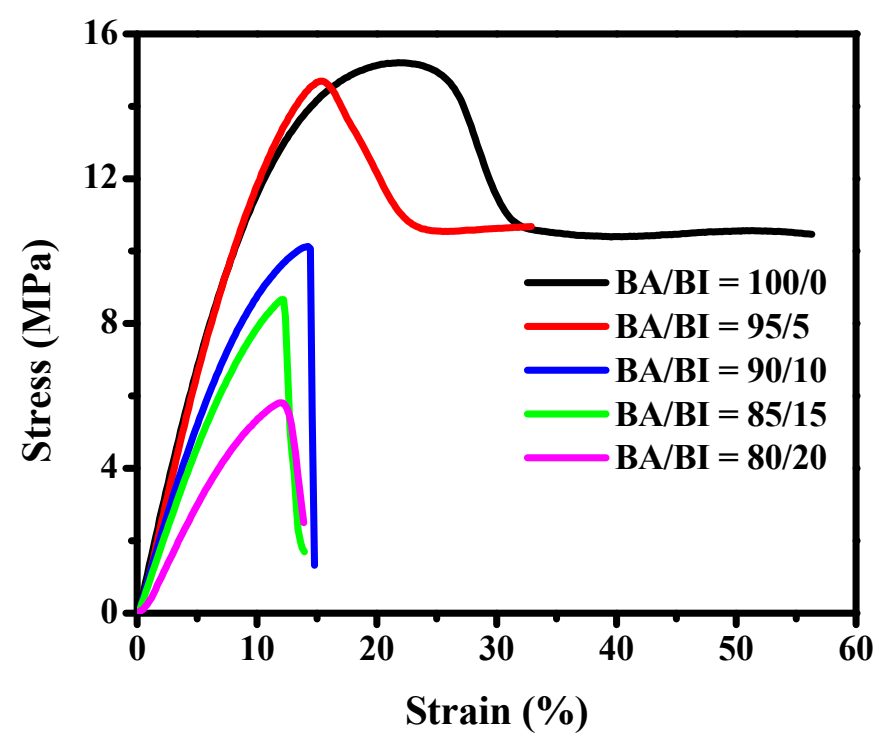

Figure 7. The stress-strain curves of PBABI copolyesters.

Table 3. Mechanical properties of PBABI copolyesters.

\begin{tabular}{cccc}
\hline Sample & Yield Strength $\mathbf{( M P a )}$ & Elongation (\%) & Young's Modulus (MPa) \\
\hline $\mathbf{B A} / \mathbf{B I}=\mathbf{1 0 0} / \mathbf{0}$ & $15.19 \pm 1.15$ & $56.13 \pm 3.99$ & $162.95 \pm 12.29$ \\
$\mathbf{B A} / \mathbf{B I}=\mathbf{9 5 / 5}$ & $14.69 \pm 1.01$ & $32.73 \pm 3.45$ & $158.45 \pm 10.45$ \\
$\mathbf{B A} / \mathbf{B I}=\mathbf{9 0} / \mathbf{1 0}$ & $10.12 \pm 0.36$ & $14.79 \pm 2.23$ & $96.08 \pm 7.82$ \\
$\mathbf{B A} / \mathbf{B I}=\mathbf{8 5} / \mathbf{1 5}$ & $8.66 \pm 0.33$ & $13.78 \pm 1.14$ & $78.72 \pm 6.26$ \\
$\mathbf{B A} / \mathbf{B I}=\mathbf{8 0} / \mathbf{2 0}$ & $5.81 \pm 0.19$ & $13.91 \pm 1.04$ & $32.19 \pm 1.45$ \\
\hline
\end{tabular}

\subsection{Non-Isothermal Crystallization Kinetics of PBABI Copolyesters}

As can be seen in Figure 8, the non-isothermal crystallization curves of PBABI copolyesters with different ratios of BA/BI were recorded at different cooling rates of $2,5,10^{\circ} \mathrm{C} \mathrm{min}{ }^{-1}$, exhibiting a single exothermic peak, which becomes broader and moves to lower temperatures as the cooling rate increased due to a different thermal equilibrium [46,47]. Increasing the heating rate from 2 to $10{ }^{\circ} \mathrm{C} \mathrm{min}^{-1}$, the initial crystallization temperatures were declined, which related to the kinetic aspects of these conditions occurring in non-equilibrium materials. 

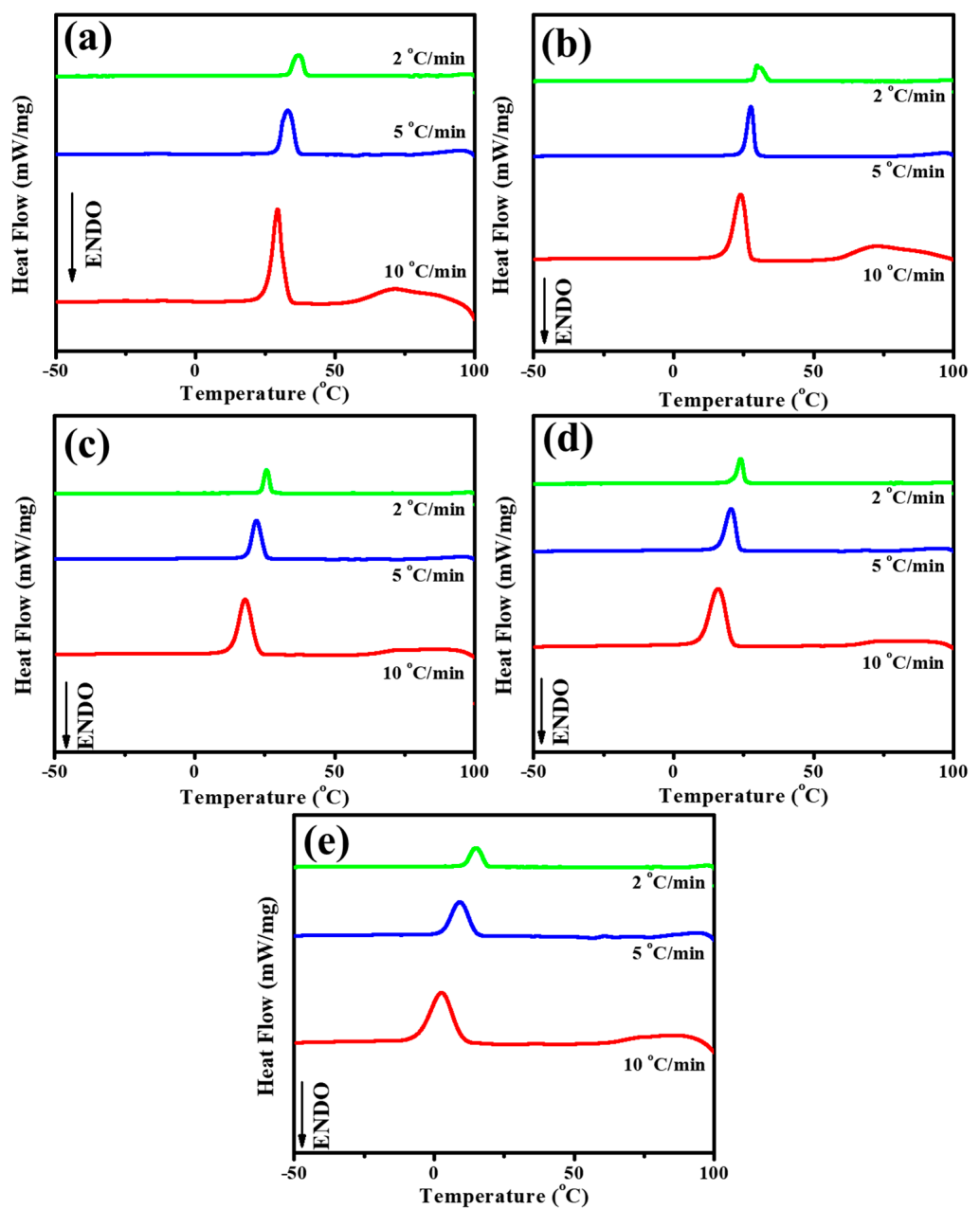

Figure 8. DSC curves of non-isothermal crystallization at different cooling rates and with a BA/BI content in (a) BA/BI = 100/0, (b) BA/BI = 95/5, (c) BA/BI =90/10, (d) BA/BI = 85/15 and (e) BA/BI = 80/20.

\subsubsection{Non-Isothermal Crystallization Kinetics Based on Avrami Equation}

The primary stage of non-isothermal crystallization could be well defined by the Avrami [48-50] in Equations (2) and (3)

$$
1-X t(\%)=e^{-K t^{n}}
$$

or

$$
\log [-\ln (1-X t(\%))]=\log (\mathrm{K})+\mathrm{n} \log (\mathrm{t})
$$

where $X t(\%)$ is the relative crystallinity, $\mathrm{K}$ is the crystallization rate constant, and $\mathrm{n}$ is the Avrami exponent, which is correlated to the growth geometry of crystals.

$$
X t(\%)=\frac{\int_{0}^{t}\left(\frac{d H_{c}}{d t}\right) d t}{\int_{0}\left(\frac{d H_{c}}{d t}\right) d t}
$$

where the $d H_{c}$ has represented the enthalpy of crystallization at the target temperature during the time interval $\mathrm{dt}$ via DSC measurement via Equation (4). The integral limits of $t$ and $\infty$ are adopted to denote the time during the crystallization occurrence and the end of the crystallization procedure, respectively. Figure S2 displayed the plot of relative crystallinity as a function of time at different cooling rates. All the experimental results were plotted with the $\log \left\{-\ln \left[1-X_{t}(\%)\right]\right\}$ as a function of $\log (t)$ at the $X_{t}(\%)$ ranged from $20-80 \%$ and were well fitted by Avrami equation at various [51-53]. (See Figure S3) All the Avrami parameters, $\mathrm{n}$ and $\mathrm{K}$ were linearly regressed to obtain from the slopes and intercepts 
of the curves for PBABI copolyesters at different cooling rates. The half-time $\left(t_{1 / 2}, \mathrm{~min}\right)$ and growth rate $\left(\mathrm{G}, \mathrm{min}^{-1}\right)$ were also calculated from Equations (5) and (6), and all the detailed information were tabulated in Table 4.

$$
\begin{gathered}
t_{1 / 2}=(\ln (2) / K)^{(1 / n)} \\
\mathrm{G}=1 / t_{1 / 2}
\end{gathered}
$$

Table 4. Non-isothermal crystallization parameters of PBABI copolyesters with varying BA/BI ratios at

\begin{tabular}{|c|c|c|c|c|c|c|c|}
\hline Sample & $\phi\left({ }^{\circ} \mathrm{C} \min ^{-1}\right)$ & ${ }^{*} \mathrm{~T}_{\mathrm{o}}\left({ }^{\circ} \mathrm{C}\right)$ & ${ }^{*} \mathrm{~T}_{\mathrm{p}}\left({ }^{\circ} \mathrm{C}\right)$ & $\mathbf{n}$ & $\mathrm{K}\left(\min ^{-n}\right)$ & $t_{1 / 2}(\min )$ & $G\left(\min ^{-1}\right)$ \\
\hline & 2 & 40.36 & 37.15 & 5.76 & 0.3449 & 1.1288 & 0.8859 \\
\hline \multirow[t]{3}{*}{$\mathrm{BA} / \mathrm{BI}=100 / 0$} & 5 & 37.63 & 33.07 & 4.28 & 0.1372 & 1.4600 & 0.6849 \\
\hline & 10 & 35.31 & 29.46 & 5.19 & 0.0008 & 3.6816 & 0.2716 \\
\hline & 2 & 34.24 & 29.63 & 3.54 & 1.7681 & 0.7676 & 1.3028 \\
\hline \multirow[t]{3}{*}{$\mathrm{BA} / \mathrm{BI}=95 / 5$} & 5 & 31.16 & 27.53 & 5.92 & 0.0271 & 1.5975 & 0.6260 \\
\hline & 10 & 28.06 & 24.01 & 3.99 & 0.0133 & 2.6935 & 0.3713 \\
\hline & 2 & 27.67 & 25.68 & 3.28 & 2.1618 & 0.7070 & 1.4145 \\
\hline \multirow[t]{3}{*}{$\mathrm{BA} / \mathrm{BI}=90 / 10$} & 5 & 25.97 & 21.99 & 3.94 & 0.4035 & 1.1472 & 0.8717 \\
\hline & 10 & 23.98 & 17.98 & 5.24 & 0.0102 & 2.2370 & 0.4470 \\
\hline & 2 & 25.92 & 23.82 & 5.92 & 0.0515 & 1.5514 & 0.6446 \\
\hline \multirow[t]{3}{*}{$\mathrm{BA} / \mathrm{BI}=85 / 15$} & 5 & 24.14 & 20.48 & 5.94 & 0.0098 & 2.0482 & 0.4882 \\
\hline & 10 & 21.77 & 15.97 & 5.62 & 0.0009 & 3.2631 & 0.3065 \\
\hline & 2 & 19.09 & 15.01 & 4.68 & 0.0352 & 1.8904 & 0.5290 \\
\hline \multirow[t]{2}{*}{$\mathrm{BA} / \mathrm{BI}=80 / 20$} & 5 & 15.75 & 9.19 & 4.21 & 0.0213 & 2.2869 & 0.4373 \\
\hline & 10 & 11.98 & 2.74 & 4.11 & 0.0033 & 3.6732 & 0.2722 \\
\hline
\end{tabular}
different cooling rates.

${ }^{*} \mathrm{~T}_{\mathrm{o}}$ and $\mathrm{T}_{\mathrm{p}}$ are the onset and peak temperatures, respectively.

Figure 9 shows the growth rate as a function of IA content for PBABI copolyesters at different cooling rates. Obviously, the crystallization rate first increased and then decreased by raising the IA content within the PBABI copolyesters at each cooling rate. The highest value of growth rate was located at the IA content of 10 mole\%, implying the crystallization rate could be enhanced with adding 10 mole\% IA into PBABI copolyesters as a nucleating site, which would improve the flexibility of the molecular chain, thus reducing the energy barrier to drive the chain diffusion into the crystal lattice to promote crystallization behavior. Subsequently, the IA molecular could hinder the chain packing behavior and disrupt the regularity of the molecular chain in the IA concentration of more than 10 mole\%. Further, the Avrami exponent of PBABI copolyesters is located around 3-5 and listed in Table 4, revealing that the crystal lattice tended to exhibit a spherical growth geometrical mechanism. The lowest half-time $\left(t_{1 / 2}\right)$ was placed in $B A / B I=90 / 10$, implying the fastest crystallization rate was obtained at the same cooling rate, as a $10 \mathrm{~mole} \%$ of IA inside the PBABI copolyesters.

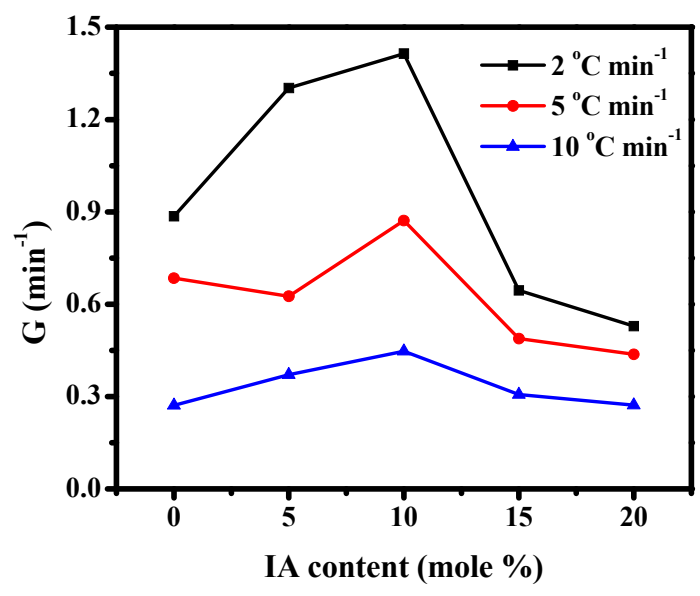

Figure 9. Plots of growth rate $(\mathrm{G})$ as a function of itaconic acid (IA) content for PBABI copolyesters at different cooling rates. IA is itaconic acid. 


\subsubsection{Non-Isothermal Crystallization Kinetics Based on Mo Equation}

Mo and colleagues have been developed a technique by merging the Avrami [49] and Ozawa [54] model to explain exactly non-isothermal crystallization kinetics [55] and the Equation (7) as follows,

$$
\ln \phi=\frac{1}{m} \ln \left[\frac{K(T)}{Z}\right]-\frac{n}{m} \ln t
$$

Here, the $F(T)=[K(T) / Z]^{1 / m}$ and $\mathrm{a}=n / m$, the Equation (7) can be modified to Equation (8):

$$
\ln \phi=\ln F(T)-a \ln t
$$

where the physical meaning of $F(T)$ is the cooling rate value chosen in each crystallization time at which the system has a defined degree of crystallinity, meaning a higher value of $F(T)$ exhibits a lower crystallization rate.

The plot of $\log (\phi)$ versus $\log (t)$ for PBABI copolyesters with a different BA/BI concentrations were presented in Figure $S 4$ and the value of $F(T)$ and a can be obtained by intercept and slope via Equation (8), as listed in Table 5. The results of proposed Mo's model that displayed an excellent linear relation could be well described as non-isothermal crystallization behavior for PBABI copolyesters.

Table 5. Non-isothermal crystallization kinetic parameters of the PBABI copolyesters with different BA/BI contents obtained by Mo's equation.

\begin{tabular}{ccccccccccc}
\hline \multirow{2}{*}{$\mathbf{X}(\mathbf{t})$} & \multicolumn{2}{c}{$\mathbf{B A} / \mathbf{B I}=\mathbf{1 0 0} / \mathbf{0}$} & \multicolumn{2}{c}{$\mathbf{B A} / \mathbf{B I}=\mathbf{9 5 / 5}$} & \multicolumn{2}{c}{$\mathbf{B A} / \mathbf{B I}=\mathbf{9 0 / 1 0}$} & \multicolumn{2}{c}{$\mathbf{B A} / \mathbf{B I}=\mathbf{8 5} / \mathbf{1 5}$} & \multicolumn{2}{c}{$\mathbf{B A} / \mathbf{B I}=\mathbf{8 0 / 2 0}$} \\
\cline { 2 - 11 } & $\mathbf{a}$ & $\mathbf{F}(\mathbf{T})$ & $\mathbf{a}$ & $\mathbf{F}(\mathbf{T})$ & $\mathbf{a}$ & $\mathbf{F}(\mathbf{T})$ & $\mathbf{a}$ & $\mathbf{F}(\mathbf{T})$ & $\mathbf{a}$ & $\mathbf{F}(\mathbf{T})$ \\
\hline 0.2 & 1.23 & 7.56 & 1.09 & 5.33 & 1.36 & 4.41 & 2.11 & 13.27 & 2.46 & 24.46 \\
0.4 & 1.25 & 9.09 & 1.14 & 6.51 & 1.45 & 5.78 & 2.13 & 21.73 & 2.35 & 34.01 \\
0.6 & 1.25 & 10.55 & 1.18 & 7.33 & 1.52 & 7.24 & 2.13 & 26.73 & 2.29 & 44.13 \\
0.8 & 1.27 & 12.63 & 1.29 & 9.77 & 1.62 & 9.49 & 2.16 & 32.76 & 2.31 & 63.21 \\
\hline
\end{tabular}

Figure 10 presents the plot $\mathrm{F}(T)$ as a function of IA content with a crystallinity at a range of $0.2-0.8$ for PBABI copolyesters. At first, the value of $F(T)$ was reduced and then raised as the increase of IA content in PBABI copolyesters at a relative crystallinity, presenting the crystallization rate increased first and then decreased depended on the IA content. Moreover, the lowest value of $F(T)$ is located in 10 mole $\%$ IA content, suggesting the BA/BI $=90 / 10$ has the highest crystallization rate. These results of Mo's model are well agreement with the Avrami model, as displayed in Figure 9.

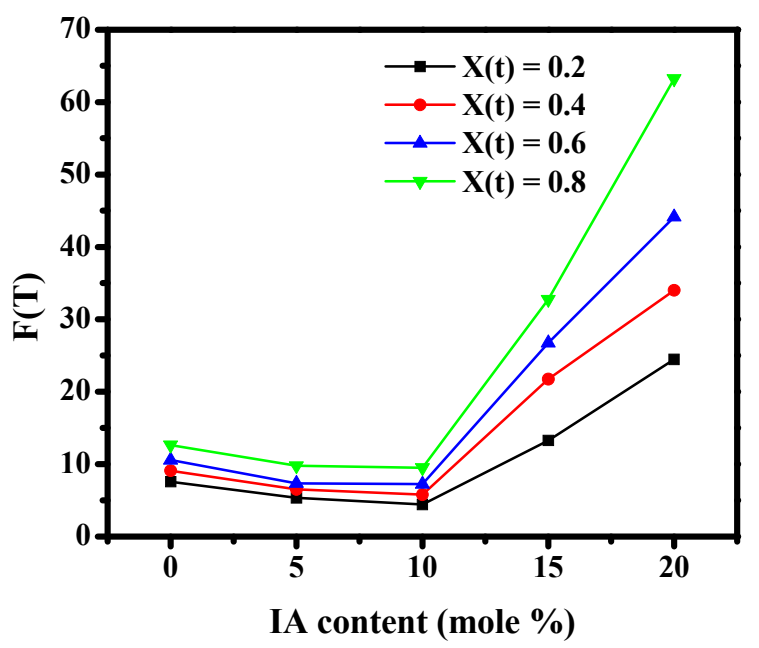

Figure 10. Plots of $F(T)$ as a function of IA content for PBABI copolyesters at a range of relative crystallinity in 0.2-0.8. IA is itaconic acid. 
Activation energy is a driving force to control the crystallization behavior of copolymers, which is associated with the energy required for the transport of crystalline chains across the inter-phase. The Kissinger model [56] is most implemented to evaluate the activation energy via the Equation (9) as follows,

$$
\frac{d\left[\ln \left(\varnothing / T_{p}^{2}\right)\right]}{d\left(1 / T_{p}\right)}=-\frac{\Delta E}{R}
$$

where $T_{\mathrm{p}}$ is the peak of crystallization temperature, $\Delta E$ is the activation energy, $R$ is the gas constant. The slope of the Equation (9) was equal to $-\Delta E / R$ and plotted in Figure S5. After that, the value of $\Delta E$ as a function of IA content was plotted in Figure 11. It can be seen that the lowest $\Delta E$ value was detected in 10 mole\% IA. The reduced activation energy is caused by the incorporating of a small amount of IA, which plays a role in determining the nucleating site within the PBABI copolyesters to accelerate the molecular chain packing. Nevertheless, as the IA concentration exceeded $10 \mathrm{~mole} \%$, the irregular molecular chain structure would be a dominant role, leading to rising the activation energy. This statement is also in good agreement with the Avrami's and Mo's results.

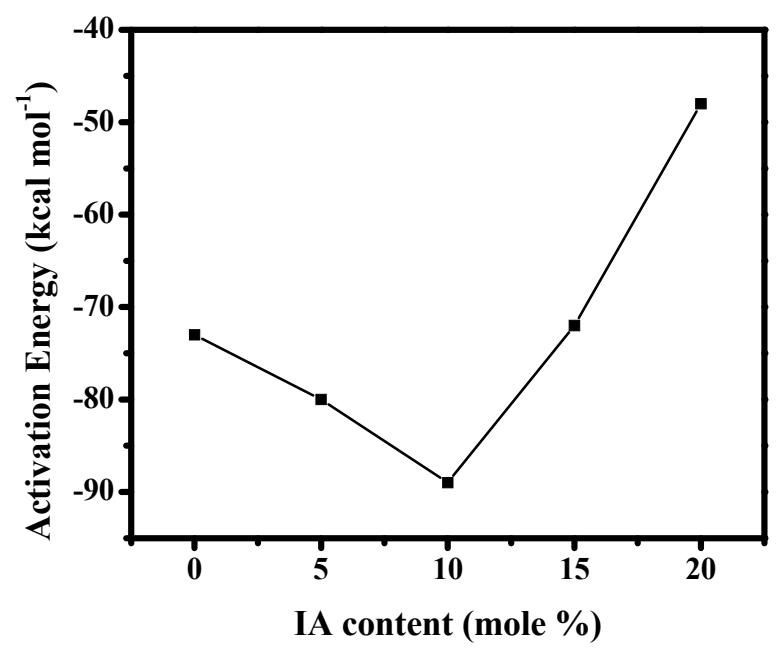

Figure 11. Plots of activation energy as a function of IA content for PBABI copolyesters. IA is itaconic acid.

The nucleation activity $(\phi)$ of non-isothermal crystallization behavior could be calculated by the Dobreva model [57] in which $B_{s}$, a parameter related to the nucleation behavior, can be estimated through following Equation (10),

$$
\ln \phi=\text { const. }-\frac{B_{s}}{2.3 \Delta T_{p}^{2}}
$$

where $\Delta T_{\mathrm{p}}=T_{\mathrm{o}}-T_{\mathrm{p}}$, the $B_{\mathrm{s}}$ can be obtained from the slope of the plot of $\ln (\phi)$ vs. $1 / 2.3 \Delta T_{\mathrm{p}}{ }^{2}$ while $\phi$ can be calculated from $B_{\mathrm{S}}$, according to the following Equation (11),

$$
\phi=\frac{B_{s}^{*}}{B_{s}^{0}}
$$

where $B_{\mathrm{s}}{ }^{*}$ and $B_{\mathrm{s}}{ }^{0}$ are the values of $B_{\mathrm{s}}$ for heterogeneous and homogeneous nucleations, respectively. As best of our knowledge, the nucleation activity decreased with inserting an additive. [57] The plot of $\ln \phi$ vs. $1 / 2.3 \Delta T_{\mathrm{p}}{ }^{2}$ for PBABI copolyesters is displayed in Figure S6, from which the results $\phi$ are calculated as listed in Table 6. For all BA/BI ratios, all the $\phi$ is below 1 and $\phi$ has a minimum value of 0.2896 at $\mathrm{BA} / \mathrm{BI}=90 / 10$. These results suggested that the existed IA had facilitated the nucleation site formed for the PBABI copolyesters in an IA content of $10 \mathrm{~mole} \%$ at a given molecular weight. 
Table 6. Nucleation activity of PBABI copolyesters with different BA/BI contents.

\begin{tabular}{ccccc}
\hline & BA/BI $=\mathbf{9 5} / \mathbf{5}$ & BA/BI $=\mathbf{9 0 / 1 0}$ & BA/BI $=\mathbf{8 5 / \mathbf { 1 5 }}$ & BA/BI = 80/20 \\
\hline$\phi$ & 0.3203 & 0.2869 & 0.4232 & 0.9581 \\
\hline
\end{tabular}

\subsection{The Effect of Different BTCA Concentrations at BA/BI =90/10 of PBABI Copolyesters}

Figure 57 exhibits the ${ }^{1} \mathrm{H}$ NMR results of PBABI copolyesters with different contents of BTCA. The resonance peaks of PBABI copolyesters with different BTCA contents were identified and assigned in $\mathrm{H}_{1}$ (1.893-1.916 ppm, 3, 4- $\mathrm{CH}_{2}$ of adipic acid), $\mathrm{H}_{2}$ (1.971-1.998 ppm, 2, 3- $\mathrm{CH}_{2}$ of 1.4-butanediol), $\mathrm{H}_{3}$ (2.654-2.677 ppm, 2, 5- $\mathrm{CH}_{2}$ of adipic acid), $\mathrm{H}_{4}$ (3.678-3.706 ppm, 2- $\mathrm{CH}_{2}$ of itaconic acid), $\mathrm{H}_{5}$ (4.415-4.438 ppm, 1, 4- $\mathrm{CH}_{2}$ of 1.4-butanediol), $\mathrm{H}_{6}$ (6.085-6.102 ppm,- $\mathrm{C}=\mathrm{CH}_{2}$ of itaconic acid), $\mathrm{H}_{7}$ (6.678-6.706 ppm, $-\mathrm{C}=\mathrm{CH}_{2}$ of itaconic acid) and $\mathrm{H}_{8}(7.072-7.102 \mathrm{ppm},-\mathrm{CH}$ of the benzenic ring in BTCA. All the chemical shift and integral values were recorded in Table 7 , revealing the calculated BTCA concentrations were taken in $0.16,0.17$ and $0.22 \mathrm{~mole} \%$ for a feed content of $0.05,0.1$ and 0.2 mole $\%$, respectively.

Table 7. Chemical shifts and the integral ratio of ${ }^{1} \mathrm{H}$ NMR spectra for PBABI copolyesters.

\begin{tabular}{ccccccccc}
\hline Sample & $\mathbf{H}_{\mathbf{1}}$ & $\mathbf{H}_{\mathbf{2}}$ & $\mathbf{H}_{\mathbf{3}}$ & $\mathbf{H}_{\mathbf{4}}$ & $\mathbf{H}_{\mathbf{5}}$ & $\mathbf{H}_{\mathbf{6}}$ & $\mathbf{H}_{\mathbf{7}}$ & $\mathbf{H}_{\mathbf{8}}$ \\
\hline \multirow{2}{*}{$\mathbf{B A} / \mathbf{B I}=\mathbf{9 0 / 1 0 - 0 . 0 5}$} & 1.893 & 1.975 & 2.654 & 3.678 & 4.415 & 6.085 & 6.678 & 7.073 \\
& $(1.003)$ & $(0.986)$ & $(1.000)$ & $(0.033)$ & $(1.021)$ & $(0.019)$ & $(0.017)$ & $(0.010)$ \\
$\mathbf{B A} / \mathbf{B I}=\mathbf{9 0 / 1 0 - 0 . 1}$ & 1.897 & 1.971 & 2.658 & 3.683 & 4.419 & 6.095 & 6.684 & 7.072 \\
& $(1.004)$ & $(0.985)$ & $(1.000)$ & $(0.045)$ & $(1.029)$ & $(0.030)$ & $(0.024)$ & $(0.011)$ \\
$\mathbf{B A} / \mathbf{B I}=\mathbf{9 0 / 1 0 - 0 . 2}$ & 1.916 & 1.998 & 2.677 & 3.706 & 4.438 & 6.102 & 6.706 & 7.102 \\
& $(1.007)$ & $(1.026)$ & $(1.000)$ & $(0.036)$ & $(1.024)$ & $(0.024)$ & $(0.021)$ & $(0.014)$ \\
\hline
\end{tabular}

Figure 12 shows the DSC traces for PBABI copolyesters to investigate the thermal response. As shown in Figure 12a, crystallization was initiated at a higher temperature with BTCA concentration of $0.05 \mathrm{~mole} \%$, and also had a larger $\Delta H_{\mathrm{c}}$, implying the crystallization behavior was correlated with the amount of BTCA. The molecular chain could be driven to stack into a crystal regime due to the nucleating effect of a smaller amount of BTCA concentration. The subsequent reheating procedure was displayed in Figure $12 \mathrm{~b}$, and to measure the $T_{\mathrm{m}}$ and $\Delta H_{\mathrm{m}}$. Then, the peak melting point was split into continuous double peaks, signifying the occurrence of competitive behavior concerning AA and IA in the crystallization region. To be more exact, an increase of BTCA concentrations can exhibit a substantial steric hindrance to limit the backbone of packing into a crystal regime owing to the coplanar conformation of BTCA, thus clearly decreasing the enthalpy of crystallization.
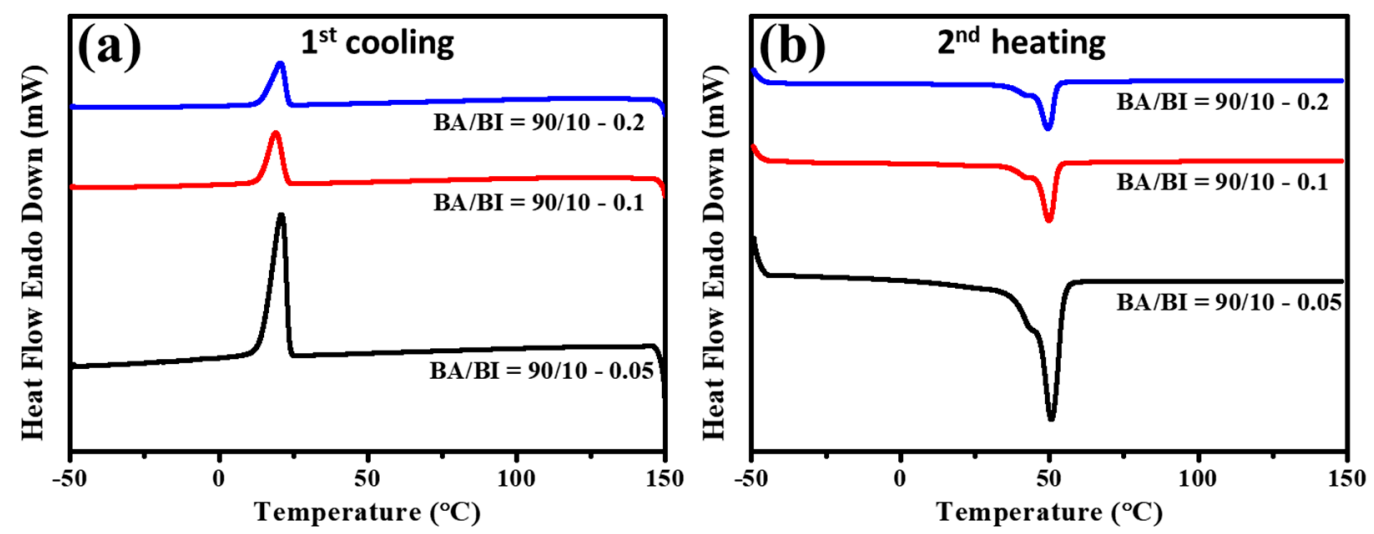

Figure 12. DSC trace of PBABI copolyesters with different concentrations of BTCA: (a) curves of cooling in the first cycle and (b) curves of reheating in the second cycle. 
Figure 13 illustrates the DMA analysis of Tan $\delta$ and storage modulus in a fixed ratio of $\mathrm{BA} / \mathrm{BI}=90 / 10$ at different concentrations of BTCA. It is manifest from Figure 13a that the Tan $\delta$ of PBABI copolyesters increased slightly at higher concentrations of BTCA, and the $\mathrm{T}_{\mathrm{g}}$ values were located around $-49.1--54.9^{\circ} \mathrm{C}$, suggesting the steric hindrance of the BTCA could restrict the side-chain motion in the amorphous zone to improve the $\mathrm{T}_{\mathrm{g}}$. As can be seen in Figure 13b, the largest storage modulus was observed at a BTCA ratio of $0.2 \mathrm{~mole} \%$, suggesting that the PBABI copolyesters in both glassy and rubbery region have a trend to be harder characteristic, attributed to the relatively higher fraction of BTCA. Alternatively, a higher BTCA concentration within PBABI copolyesters revealed the more coplanar benzene ring to produce a more robust partial cross-linking structure, which could improve the mechanical properties of the PBABI copolyesters.
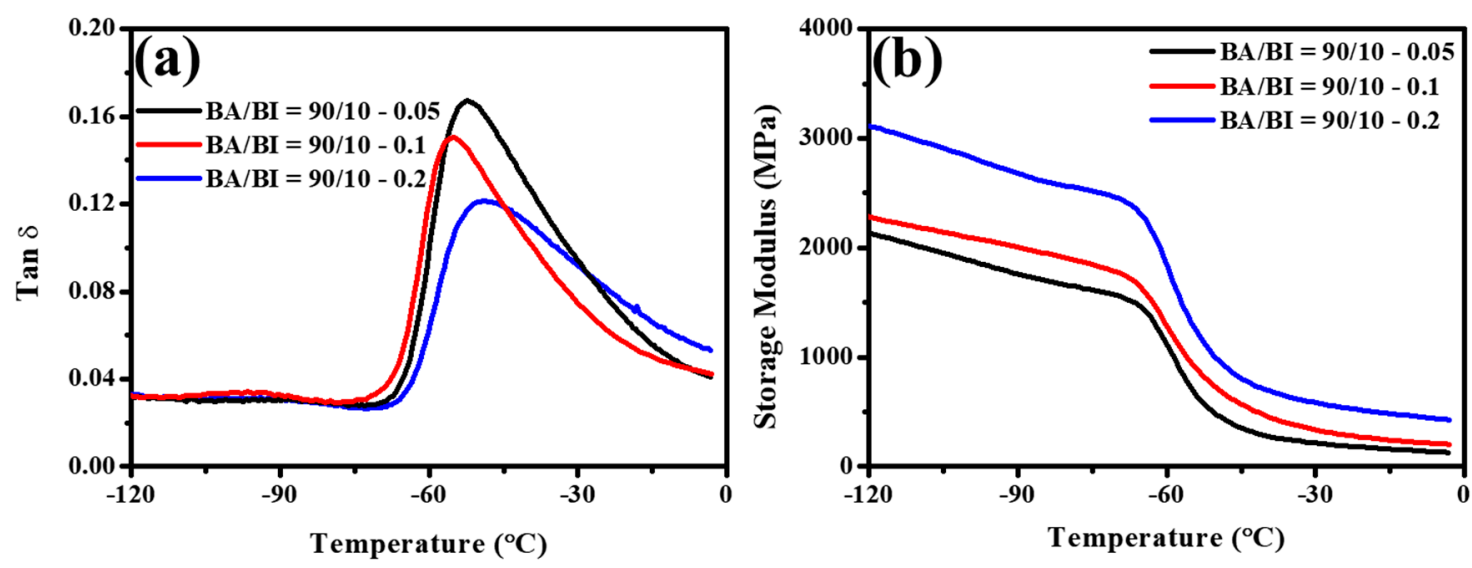

Figure 13. DMA results for (a) Tan $\delta$ and (b) storage modulus of PBABI copolyesters at different concentrations of BTCA.

Thermal property measurements are summarized in Table 8. At a BTCA content of 0.05 mole $\%$, the onset point of $\mathrm{T}_{\mathrm{C}}$ was reached at a temperature of $24.5^{\circ} \mathrm{C}$, indicating it could crystallize at a higher temperature and grew a better-sized spherulite than other concentrations of BTCA, which was also evident in the higher $\Delta H_{\mathrm{c}}$ value of $-56.5 \mathrm{~mJ} \mathrm{mg}^{-1}$. The DSC trace of $T_{\mathrm{m}}$ in the reheating procedure had a similar trajectory in continuous double peaks around $40-50{ }^{\circ} \mathrm{C}$, and the $\Delta H_{\mathrm{m}}$ values were carried out $51.2,47.9$ and $38.2 \mathrm{~mJ} \mathrm{mg}^{-1}$ for BTCA concentrations of $0.05,0.1$ and $0.2 \mathrm{~mole} \%$, respectively. It is interesting that the most considerable value of $\Delta H_{\mathrm{m}}$ occurred at a BTCA ratio of $0.05 \mathrm{~mole} \%$, implying a small amount of BTCA concentration may improve the thermal behavior.

Table 8. Thermal property of PBABI copolyesters.

\begin{tabular}{|c|c|c|c|c|c|c|}
\hline Sample & $\begin{array}{l}{ }^{*} T_{\mathrm{g}} \\
\left({ }^{\circ} \mathrm{C}\right)\end{array}$ & $\begin{array}{c}T_{\mathrm{c}} \text { (onset) } \\
\quad\left({ }^{\circ} \mathrm{C}\right)\end{array}$ & $\begin{array}{c}T_{\mathrm{c}} \text { (peak) } \\
\left({ }^{\circ} \mathrm{C}\right)\end{array}$ & $\underset{\left(m J \mathrm{mg}^{-1}\right)}{\Delta H_{\mathrm{c}}}$ & $\begin{array}{l}T_{\mathrm{m}} \\
\left({ }^{\circ} \mathrm{C}\right)\end{array}$ & $\begin{array}{c}\Delta H_{\mathrm{m}} \\
\left(\mathrm{mJ} \mathrm{m} \mathrm{g}^{-1}\right)\end{array}$ \\
\hline BA/BI $=90 / 10-0.05$ & -52.4 & 24.5 & 21.1 & -56.5 & $43.4,50.8$ & 51.2 \\
\hline $\mathrm{BA} / \mathrm{BI}=90 / 10-0.1$ & -54.9 & 23.5 & 19.1 & -52.9 & $41.9,49.8$ & 47.9 \\
\hline $\mathrm{BA} / \mathrm{BI}=90 / 10-0.2$ & -49.1 & 23.4 & 20.8 & -41.4 & $42.1,49.6$ & 38.2 \\
\hline
\end{tabular}

The absorption peak of FT-IR spectra in PBABI copolyesters at various ratios of BTCA is displayed in Figure S8. It is not surprising that the FT-IR curve of each ratio of BTCA in BA/BI $=90 / 10$ exhibited a similar absorption position and mentioned in Figure 2. Otherwise, XRD patterns for BA/BI =90/10 at BTCA concentrations from 0.05 to 0.2 mole $\%$ are presented in Figure S9. The values of $2 \theta$ of $\mathrm{BA} / \mathrm{BI}=90 / 10$ with BTCA of $0.05-0.2 \mathrm{~mole} \%$ of PBABI copolyesters were identified around $21.97^{\circ}$, $22.66^{\circ}$ and $24.38^{\circ}$, which relates to the crystal lattices of (110), (020) and (020), respectively. All the intensity of crystal lattices decreased in a BTCA ratio from 0.05 to $0.2 \mathrm{~mole} \%$, which indicated that the degree of crystallization for PBABI copolyester was reduced by increasing the concentration of BTCA. 
The most considerable $\Delta H_{\mathrm{m}}$ value was also observed at a ratio of $0.05 \mathrm{~mole} \%$. However, the intensity of feature peaks of (110) and (020) decreased gradually with the BTCA was increased to 0.1 and $0.2 \mathrm{~mole} \%$, implying the crystal region was reduced as the BTCA strengthened. More specifically, the higher concentration of BTCA can increase the steric hindrance to disrupt the crystal regime, and the crystal region becomes smaller in lowering the $\Delta \mathrm{H}_{\mathrm{m}}$. Hence, the BTCA acted an essential role in regulating the thermal behavior and mechanical property.

The stress-strain curves of PBABI copolyesters at different ratios of BTCA were measured, as illustrated in Figure 14 and summarized in Table 9. The yield strength was raised with an increase of BTCA concentration due to the more content of BTCA, and the elongation was decreased corresponding. The Young's modulus could be enhanced dramatically when a small amount of BTCA was copolymerized into the PBABI copolyesters; hence, the mechanical property can be tuned through the adjustment of BTCA concentrations. However, the trend in stress deviation increased with an increase in the BTCA concentration, which could be ascribed to the higher partial degree of cross-linking. Fisher and colleagues have been studied unsaturated poly(propylene fumarate) after UV-Vis irradiation, proposed that the 3D network structure may well improve the tensile properties with different concentrations and types of cross-linking modifier [58].

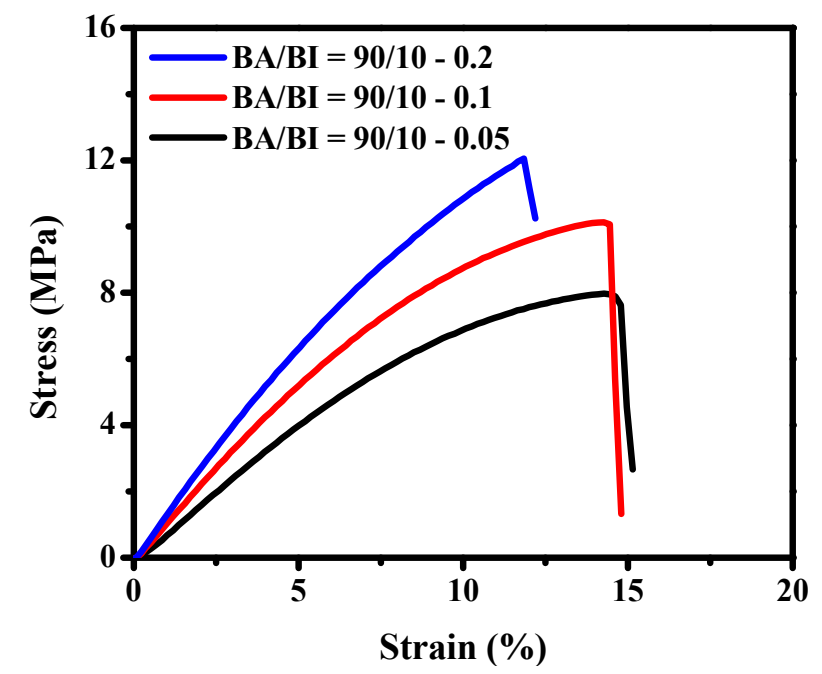

Figure 14. The stress-strain curves of PBABI copolyesters at different concentrations of BTCA.

Table 9. Mechanical properties of PBABI copolyesters.

\begin{tabular}{cccc}
\hline Sample & Yield Strength (MPa) & Elongation (\%) & $\begin{array}{c}\text { Young's Modulus } \\
\text { (MPa) }\end{array}$ \\
\hline BA/BI = 90/10-0.05 & $7.97 \pm 0.04$ & $15.03 \pm 2.56$ & $56.49 \pm 3.41$ \\
BA/BI = 90/10-0.1 & $10.12 \pm 0.36$ & $14.79 \pm 2.23$ & $96.08 \pm 7.82$ \\
BA/BI = 90/10-0.2 & $11.85 \pm 0.14$ & $12.19 \pm 2.11$ & $141.39 \pm 7.97$ \\
\hline
\end{tabular}

\section{Conclusions}

A series of unsaturated PBABI copolyesters with the BTCA were systematically synthesized via bulk polymerization and identified the structure through ${ }^{1} \mathrm{H}$ NMR and FT-IR analysis. The $T_{\mathrm{m}}, \mathrm{T}_{\mathrm{c}}$ and $T_{\mathrm{g}}$ of the PBABI copolyesters were found in a range of $30-50$ and $10-30$, and $-51--55^{\circ} \mathrm{C}$, respectively, and has an excellent thermal property at a $T_{\mathrm{d}-5 \%}$ above $330^{\circ} \mathrm{C}$. The feature peak of XRD was located in the $2 \theta$ values of $21.75^{\circ}, 22.41^{\circ}$ and $24.12^{\circ}$ for the crystal panels of (110), (020) and (020), respectively; then the crystallinity from the XRD pattern was decreased from $42.4 \%$ to $34.2 \%$ with gradually raising the $\mathrm{BA} / \mathrm{BI}$ ratio to $20 \mathrm{~mole} \%$ suggesting sufficient IA content could interrupt chain packing into the ordered state. The Young's modulus can be tuned, ranging between 32.19-168.45 MPa at different $\mathrm{BA} / \mathrm{BI}$ ratios. The highest crystallization rate was measured at the $\mathrm{BA} / \mathrm{BI}=90 / 10$ by non-isothermal 
crystallization kinetics analysis. Furthermore, the BTCA played a crucial role in controlling the enthalpy of crystallization and a higher concentration of BTCA could increase the steric hindrance to disturb the crystal regime. The Young's modulus could be dramatically enhanced by the increase of $0.1 \mathrm{~mole} \%$ of BTCA at BA/BI = 90/10; hence, the PBABI copolyesters could be coated on the 3D air mesh fabric for a phase change material usage. Moreover, advantages of the PBABI copolyesters could offer biodegradable, low $T_{\mathrm{m}}$ and UV-Vis curable to utilize in smart textiles and tunable thermal behavior and mechanical property through the adjustment of IA content and BTCA concentrations.

Supplementary Materials: The following are available online at http://www.mdpi.com/2073-4360/12/5/1160/s1.

Author Contributions: Conceptualization, C.-W.C.; Data curation, T.-S.H. and K.-W.H.; Formal analysis, C.-W.C.; Funding acquisition, S.-P.R.; Investigation, C.-W.C.; Methodology, C.-W.C.; Supervision, S.-P.R.; Writing-original draft, C.-W.C.; Writing-review \& editing, C.-W.C. All authors have read and agreed to the published version of the manuscript.

Funding: The authors gratefully acknowledge the financial support from the Ministry of Science and Technology of Taiwan (MOST 107-3017-F-027-001).

Conflicts of Interest: The authors declare no conflict of interest.

\section{References}

1. Zia, K.M.; Noreen, A.; Zuber, M.; Tabasum, S.; Mujahid, M. Recent developments and future prospects on bio-based polyesters derived from renewable resources: A review. Int. J. Biol. Macromol. 2016, 82, 1028-1040. [CrossRef] [PubMed]

2. Cameron, D.J.A.; Shaver, M.P. Aliphatic polyester polymer stars: Synthesis, properties and applications in biomedicine and nanotechnology. Chem. Soc. Rev. 2011, 40, 1761-1776. [CrossRef] [PubMed]

3. Vert, M.; Li, S.M.; Spenlehauer, G.; Guerin, P. Bioresorbability and biocompatibility of aliphatic polyesters. J. Mater. Sci. Mater. Med. 1992, 3, 432-446. [CrossRef]

4. Douka, A.; Vouyiouka, S.; Papaspyridi, L.-M.; Papaspyrides, C.D. A review on enzymatic polymerization to produce polycondensation polymers: The case of aliphatic polyesters, polyamides and polyesteramides. Prog. Polym. Sci. 2018, 79, 1-25. [CrossRef]

5. Vert, M. Aliphatic Polyesters: Great Degradable Polymers That Cannot Do Everything t. Biomacromolecules 2005, 6, 538-546. [CrossRef]

6. Díaz, A.; Katsarava, R.; Puiggalí, J. Synthesis, Properties and Applications of Biodegradable Polymers Derived from Diols and Dicarboxylic Acids: From Polyesters to Poly(ester amide)s. Int. J. Mol. Sci. 2014, 15, 7064-7123. [CrossRef]

7. Zhu, C.; Zhang, Z.; Liu, Q.; Wang, Z.; Jin, J. Synthesis and biodegradation of aliphatic polyesters from dicarboxylic acids and diols. J. Appl. Polym. Sci. 2003, 90, 982-990. [CrossRef]

8. Zhou, C.; Wei, Z.; Yu, Y.; Shao, S.; Leng, X.; Wang, Y.; Li, Y. Biobased long-chain aliphatic polyesters of 1,12-dodecanedioic acid with a variety of diols: Odd-even effect and mechanical properties. Mater. Today Commun. 2019, 19, 450-458. [CrossRef]

9. Dai, J.; Ma, S.; Wu, Y.; Zhu, J.; Liu, X. High bio-based content waterborne UV-curable coatings with excellent adhesion and flexibility. Prog. Org. Coat. 2015, 87, 197-203. [CrossRef]

10. Dai, J.; Ma, S.; Liu, X.; Han, L.; Wu, Y.; Dai, X.; Zhu, J. Synthesis of bio-based unsaturated polyester resins and their application in waterborne UV-curable coatings. Prog. Org. Coat. 2015, 78, 49-54. [CrossRef]

11. Fidanovski, B.Z.; Spasojevic, P.M.; Panic, V.V.; Seslija, S.I.; Spasojevic, J.P.; Popovic, I.G. Synthesis and characterization of fully bio-based unsaturated polyester resins. J. Mater. Sci. 2018, 53, 4635-4644. [CrossRef]

12. Mehta, L.B.; Wadgaonkar, K.K.; Jagtap, R.N. Synthesis and characterization of high bio-based content unsaturated polyester resin for wood coating from itaconic acid: Effect of various reactive diluents as an alternative to styrene. J. Dispers. Sci. Technol. 2019, 40, 756-765. [CrossRef]

13. Farmer, T.J.; Comerford, J.W.; Pellis, A.; Robert, T. Post-polymerization modification of bio-based polymers: Maximizing the high functionality of polymers derived from biomass: Post-polymerization modification of bio-based polymers. Polym. Int. 2018, 67, 775-789. [CrossRef] 
14. Ali, M.A.; Tateyama, S.; Oka, Y.; Kaneko, D.; Okajima, M.K.; Kaneko, T. Syntheses of high-performance biopolyamides derived from itaconic acid and their environmental corrosion. Macromolecules 2013, 46, 3719-3725. [CrossRef]

15. Kumar, S.; Samal, S.K.; Mohanty, S.; Nayak, S.K. Synthesis and characterization of itaconic-based epoxy resins. Polym. Adv. Technol. 2018, 29, 160-170. [CrossRef]

16. Sanchez, I.C.; Eby, R.K. Crystallization of random copolymers. J. Res. Natl. Bur. Stand. Sect. Phys. Chem. 1973, 77A, 353. [CrossRef]

17. Moore, O.B.; Hanson, P.-A.; Comerford, J.W.; Pellis, A.; Farmer, T.J. Improving the Post-polymerization Modification of Bio-Based Itaconate Unsaturated Polyesters: Catalyzing Aza-Michael Additions With Reusable Iodine on Acidic Alumina. Front. Chem. 2019, 7, 501. [CrossRef]

18. Kim, J.; Kong, Y.P.; Niedzielski, S.M.; Singh, R.K.; Putnam, A.J.; Shikanov, A. Characterization of the crosslinking kinetics of multi-arm poly(ethylene glycol) hydrogels formed via Michael-type addition. Soft Matter 2016, 12, 2076-2085. [CrossRef]

19. Poulopoulou, N.; Kantoutsis, G.; Bikiaris, D.N.; Achilias, D.S.; Kapnisti, M.; Papageorgiou, G.Z. Biobased Engineering Thermoplastics: Poly(butylene 2,5-furandicarboxylate) Blends. Polymers 2019, 11, 937. [CrossRef]

20. Guidotti, G.; Genovese, L.; Soccio, M.; Gigli, M.; Munari, A.; Siracusa, V.; Lotti, N. Block Copolyesters Containing 2,5-Furan and trans-1,4-Cyclohexane Subunits with Outstanding Gas Barrier Properties. Int. J. Mol. Sci. 2019, 20, 2187. [CrossRef]

21. Maniar, D.; Jiang, Y.; Woortman, A.J.J.; van Dijken, J.; Loos, K. Furan-Based Copolyesters from Renewable Resources: Enzymatic Synthesis and Properties. ChemSusChem 2019, 12, 990-999. [CrossRef] [PubMed]

22. Wu, L.; Mincheva, R.; Xu, Y.; Raquez, J.-M.; Dubois, P. High Molecular Weight Poly(butylene succinate-co-butylene furandicarboxylate) Copolyesters: From Catalyzed Polycondensation Reaction to Thermomechanical Properties. Biomacromolecules 2012, 13, 2973-2981. [CrossRef] [PubMed]

23. Yang, Z.-Y.; Chen, C.-W.; Rwei, S.-P. Influence of asymmetric substituent group 2-methyl-1,3-propanediol on bio-based poly(propylene furandicarboxylate) copolyesters. Soft Matter 2020, 16, 402-410. [CrossRef] [PubMed]

24. Chan, H.; Cho, C.; Hsu, K.; He, C.; Kuo, C.; Chu, C.; Chen, Y.; Chen, C.; Rwei, S. Smart Wearable Textiles with Breathable Properties and Repeatable Shaping in In Vitro Orthopedic Support from a Novel Biomass Thermoplastic Copolyester. Macromol. Mater. Eng. 2019, 304, 1900103. [CrossRef]

25. Cho, C.-J.; Chang, Y.-S.; Lin, Y.-Z.; Jiang, D.-H.; Chen, W.-H.; Lin, W.-Y.; Chen, C.-W.; Rwei, S.-P.; Kuo, C.-C. Green electrospun nanofiber membranes filter prepared from novel biomass thermoplastic copolyester: Morphologies and filtration properties. J. Taiwan Inst. Chem. Eng. 2020, 106, 206-214. [CrossRef]

26. Hsu, K.-H.; Chen, C.-W.; Wang, L.-Y.; Chan, H.-W.; He, C.-L.; Cho, C.-J.; Rwei, S.-P.; Kuo, C.-C. Bio-based thermoplastic poly(butylene succinate-co-propylene succinate) copolyesters: Effect of glycerol on thermal and mechanical properties. Soft Matter 2019, 15, 9710-9720. [CrossRef]

27. Chen, C.-W.; Hsu, T.-S.; Rwei, S.-P. Effect of Ethylenediaminetetraacetic Acid on Unsaturated Poly(Butylene Adipate-Co-Butylene Itaconate) Copolyester with Low-Melting Point and Controllable Hardness. Polymers 2019, 11, 611. [CrossRef]

28. Chen, C.-W.; Hsu, T.-S.; Rwei, S.-P. Isothermal Kinetics of Poly(butylene adipate-co-butylene itaconate) Copolyesters with Ethylenediaminetetraacetic Acid. ACS Omega 2020, 5, 3080-3089. [CrossRef]

29. Xiao, X.; Sui, C.; Han, L.; Liu, J.; Feng, B. Self-assembly of triorganotin(IV) moiety with 1,2,4,5-benzenetetracarboxylic acid: Syntheses, characterizations, and influence of solvent on the molecular structure (II). Heteroat. Chem. 2017, 28, e21356. [CrossRef]

30. Wang, Y.; Tang, L.; Wang, Y. New Hydrogen-bonded Supramolecular Hydrogels and Fibers Derived from 1,2,4,5-Benzenetetracarboxylic Acid and 4-Hydroxypyridine. Chem. Lett. 2006, 35, 548-549. [CrossRef]

31. Karki, S.; Friščić, T.; Jones, W. Control and interconversion of cocrystal stoichiometry in grinding: Stepwise mechanism for the formation of a hydrogen-bonded cocrystal. CrystEngComm 2009, 11, 470-481. [CrossRef]

32. Tang, T.; Moyori, T.; Takasu, A. Isomerization-Free Polycondensations of Cyclic Anhydrides with Diols and Preparation of Polyester Gels Containing Cis or Trans Carbon Double Bonds via Photo-Cross-Linking and Isomerization in the Gels. Macromolecules 2013, 46, 5464-5472. [CrossRef] 
33. Brännström, S.; Finnveden, M.; Johansson, M.; Martinelle, M.; Malmström, E. Itaconate based polyesters: Selectivity and performance of esterification catalysts. Eur. Polym. J. 2018, 103, 370-377. [CrossRef]

34. Ina Schoon; Marcel Kluge; Steven Eschig; Tobias Robert Catalyst Influence on Undesired Side Reactions in the Polycondensation of Fully Bio-Based Polyester Itaconates. Polymers 2017, 9, 693. [CrossRef] [PubMed]

35. Brännström, S.; Malmström, E.; Johansson, M. Biobased UV-curable coatings based on itaconic acid. J. Coat. Technol. Res. 2017, 14, 851-861. [CrossRef]

36. Tang, T.; Takasu, A. Facile synthesis of unsaturated polyester-based double-network gels via chemoselective cross-linking using Michael addition and subsequent UV-initiated radical polymerization. RSC Adv. 2015, 5, 819-829. [CrossRef]

37. Wu, M.C.; Woo, E. Effects of $\alpha$-form or $\beta$-form nuclei on polymorphic crystalline morphology of poly(butylene adipate). Polym. Int. 2005, 54,1681-1688. [CrossRef]

38. Woo, E.M.; Wu, M.C. Thermal and X-ray analysis of polymorphic crystals, melting, and crystalline transformation in poly(butylene adipate). J. Polym. Sci. Part B Polym. Phys. 2005, 43, 1662-1672. [CrossRef]

39. Gao, C.; Wang, J.; Han, S.; Hu, Z.; Liu, Y. Copolymerization modification of poly (butylene itaconate). In Proceedings of the AIP Conference Proceedings, Chongqing City, China, 27-28 May 2017; Volume 1864, p. 020221.

40. Wang, H.; Gao, Z.; Yang, X.; Liu, K.; Zhang, M.; Qiang, X.; Wang, X. Epitaxial Crystallization Behavior of Poly(butylene adipate) on Orientated Poly(butylene succinate) Substrate. Polymers 2018, 10, 110. [CrossRef]

41. Gan, Z.; Abe, H.; Doi, Y. Temperature-Induced Polymorphic Crystals of Poly(butylene adipate). Macromol. Chem. Phys. 2002, 203, 2369-2374. [CrossRef]

42. Hou, C.; Li, H.; Sun, X.; Yan, S.; Wang, Y.; Chen, S. The dependence of the $\beta$-to- $\alpha$ phase transition behavior of poly(1,4-butylene adipate) on phase separated morphology in its blends with poly(vinylidene fluoride). Phys. Chem. Chem. Phys. 2018, 20, 15718-15724. [CrossRef] [PubMed]

43. Minke, R.; Blackwell, J. Polymorphic structures of poly(tetramethylene adipate). J. Macromol. Sci. Part B 1979, 16, 407-417. [CrossRef]

44. Noguchi, K.; Kondo, H.; Ichikawa, Y.; Okuyama, K.; Washiyama, J. Molecular and crystal structure of poly(tetramethylene adipate) $\alpha$ form based on synchrotron X-ray fiber diffraction. Polymer 2005, 46, 10823-10830. [CrossRef]

45. Panic, V.V.; Seslija, S.I.; Popovic, I.G.; Spasojevic, V.D.; Popovic, A.R.; Nikolic, V.B.; Spasojevic, P.M. Simple one-pot synthesis of fully biobased unsaturated polyester resins based on itaconic acid. Biomacromolecules 2017, 18, 3881-3891. [CrossRef]

46. Xiao, J.; Zhang, H.; Wan, X.; Zhang, D.; Zhou, Q.-F.; Woo, E.M.; Turner, S.R. Effect of rod-like imide unit on crystallization of copoly(ethylene terephthalate-imide). Polymer 2002, 43, 7377-7387. [CrossRef]

47. Xiao, J.; Zhang, H.; Wan, X.; Zhang, D.; Zhou, Q.-F.; Woo, E.M.; Turner, S.R. Crystallization kinetics of new copoly(ethylene terephthalate-imide)s. Polymer 2002, 43, 3683-3690. [CrossRef]

48. Müller, A.J.; Michell, R.M.; Lorenzo, A.T. Isothermal Crystallization Kinetics of Polymers. In Polymer Morphology; Guo, Q., Ed.; John Wiley \& Sons, Inc.: Hoboken, NJ, USA, 2016; pp. 181-203, ISBN 978-1-118-89275-6.

49. Avrami, M. Kinetics of Phase Change. II Transformation-Time Relations for Random Distribution of Nuclei. J. Chem. Phys. 1940, 8, 212-224. [CrossRef]

50. Lu, X.F.; Hay, J.N. Isothermal crystallization kinetics and melting behaviour of poly(ethylene terephthalate). Polymer 2001, 42, 9423-9431. [CrossRef]

51. Keridou, I.; del Valle, L.J.; Funk, L.; Turon, P.; Franco, L.; Puiggalí, J. Non-Isothermal Crystallization Kinetics of Poly(4-Hydroxybutyrate) Biopolymer. Molecules 2019, 24, 2840. [CrossRef]

52. Xie, W.-J.; Zhou, X.-M. Non-isothermal crystallization kinetics and characterization of biodegradable poly(butylene succinate-co-neopentyl glycol succinate) copolyesters. Mater. Sci. Eng. C 2015, 46, 366-373. [CrossRef]

53. Yarici, T.; Kodal, M.; Ozkoc, G. Non-isothermal crystallization kinetics of Poly(Butylene succinate) (PBS) nanocomposites with different modified carbon nanotubes. Polymer 2018, 146, 361-377. [CrossRef]

54. Ozawa, T. Kinetics of non-isothermal crystallization. Polymer 1971, 12, 150-158. [CrossRef]

55. Liu, T.; Mo, Z.; Wang, S.; Zhang, H. Nonisothermal melt and cold crystallization kinetics of poly(aryl ether ether ketone ketone). Polym. Eng. Sci. 1997, 37, 568-575. [CrossRef]

56. Kissinger, H.E. Reaction Kinetics in Differential Thermal Analysis. Anal. Chem. 1957, 29, $1702-1706$. [CrossRef] 
57. Dobreva, A.; Alonso, M.; Gonzalez, M.; Gonzalez, A.; de Saja, J.A. A non-isothermal differential scanning calorimetry method for the determination of specific surface energies in polymer crystals. Thermochim. Acta 1995, 258, 197-204. [CrossRef]

58. Fisher, J.P.; Timmer, M.D.; Holland, T.A.; Dean, D.; Engel, P.S.; Mikos, A.G. Photoinitiated Cross-Linking of the Biodegradable Polyester Poly(propylene fumarate). Part I. Determination of Network Structure. Biomacromolecules 2003, 4, 1327-1334. [CrossRef]

(C) 2020 by the authors. Licensee MDPI, Basel, Switzerland. This article is an open access article distributed under the terms and conditions of the Creative Commons Attribution (CC BY) license (http://creativecommons.org/licenses/by/4.0/). 